\title{
Translating land cover/land use classifications to habitat taxonomies for landscape monitoring: a Mediterranean assessment
}

\author{
Valeria Tomaselli • Panayotis Dimopoulos • Carmela Marangi • Athanasios S. Kallimanis • \\ Maria Adamo $\cdot$ Cristina Tarantino $\cdot$ Maria Panitsa $\cdot$ Massimo Terzi $\cdot$ \\ Giuseppe Veronico · Francesco Lovergine • Harini Nagendra • Richard Lucas • \\ Paola Mairota $\cdot$ Caspar A. Mücher $\cdot$ Palma Blonda
}

Received: 12 September 2012/ Accepted: 19 February 2013/Published online: 8 March 2013

(C) The Author(s) 2013. This article is published with open access at Springerlink.com

\begin{abstract}
Periodic monitoring of biodiversity changes at a landscape scale constitutes a key issue for conservation managers. Earth observation (EO) data offer a potential solution, through direct or indirect mapping of species or habitats. Most national and international programs rely on the use of land cover (LC) and/or land use (LU) classification systems. Yet, these are not as clearly relatable to biodiversity in comparison to habitat classifications, and provide less scope for monitoring. While a conversion from $\mathrm{LC} / \mathrm{LU}$ classification to habitat classification can be of great utility, differences in definitions and criteria have so far limited the establishment of a unified approach for such translation between these two classification systems.
\end{abstract}

V. Tomaselli $(\bowtie) \cdot$ M. Terzi · G. Veronico

National Research Council-Institute of Plant Genetics

(CNR-IGV), via G. Amendola 165/A, 70126 Bari, Italy

e-mail: valeria.tomaselli@igv.cnr.it

P. Dimopoulos · A. S. Kallimanis - M. Panitsa

Department of Environmental and Natural Resources

Management, University of Ioannina, Seferi 2,

30100 Agrinio, Greece

C. Marangi

National Research Council-Institute for applied

Mathematics "Mauro Picone" (CNR-IAC),

via G. Amendola 122, 70126 Bari, Italy

M. Adamo - C. Tarantino - F. Lovergine - P. Blonda National Research Council-Institute of Intelligent Systems for Automation (CNR-ISSIA), via G. Amendola 122, 70126 Bari, Italy
Focusing on five Mediterranean NATURA 2000 sites, this paper considers the scope for three of the most commonly used global LC/LU taxonomies-CORINE Land Cover, the Food and Agricultural Organisation (FAO) land cover classification system (LCCS) and the International Geosphere-Biosphere Programme to be translated to habitat taxonomies. Through both quantitative and expert knowledge based qualitative analysis of selected taxonomies, FAO-LCCS turns out to be the best candidate to cope with the complexity of habitat description and provides a framework for EO and in situ data integration for habitat mapping, reducing uncertainties and class overlaps and bridging the gap between LC/LU and habitats domains for

\author{
H. Nagendra \\ Ashoka Trust for Research in Ecology and the \\ Environment, Royal Enclave, Srirampura, Jakkur P.O., \\ Bangalore 560064, India \\ R. Lucas \\ Institute of Geography and Earth Sciences, Aberystwyth \\ University, Aberystwyth, Ceredigion SY23 3DB, UK \\ P. Mairota \\ Dipartimento di Scienze Agro-Ambientali e Territoriali, \\ Università degli Studi di Bari "Aldo Moro", via Orabona, \\ 4, 70125 Bari, Italy \\ C. A. Mücher \\ Alterra, Wageningen UR, Droevendaalsesteeg 3, \\ 6708 PB Wageningen, The Netherlands
}


landscape monitoring - a major issue for conservation. This study also highlights the need to modify the FAOLCCS hierarchical class description process to permit the addition of attributes based on class-specific expert knowledge to select multi-temporal (seasonal) EO data and improve classification. An application of LC/LU to habitat mapping is provided for a coastal Natura 2000 site with high classification accuracy as a result.

Keywords Mapping - Land cover · Land use · Habitat · Earth observation - Taxonomies .

Natura $2000 \cdot$ Classification schemes

\section{Introduction}

Effective and timely multi-annual biodiversity monitoring of protected sites and other endangered and biologically important landscapes is critical for detecting changes which might impact on a site's conservation status, quality and resources (Townsend et al. 2009). Such monitoring is essential to evaluate the effectiveness of conservation policies in protecting biodiversity and ecosystems from human activities (Vačkář et al. 2012). Earth observation (EO) data offer significant opportunities for assessing and monitoring habitats and their contained biodiversity, not least because of the availability of data from past and current spaceborne missions with continuity provided by planned future missions (Vanden Borre et al. 2011). Over the past two to three decades, data from High Resolution (HR) sensors (i.e., spatial resolution: 3-30 m) on board platforms such as the Landsat TM/ETM + and SPOT have routinely provided synoptic spatial views of expansive landscapes and regions, allowing maps of land covers (LC) and land use (LU) to be generated and intra-annual and inter-annual changes quantified. In recent years, the advent of very high resolution (VHR) satellites (i.e., spatial resolution: $<3 \mathrm{~m}$ ) has also provided opportunities for more detailed mapping and studies of changes in habitat coverage, landscape fragmentation, and human pressure, albeit over smaller areas through comparison with pre-existing validated fine-grain (1:5,000 or better) maps obtained by orthophoto visual interpretation and in-field campaigns.

However, the focus on LC/LU mapping in many countries and regions has distracted from the need to provide detailed information on habitats. Habitats offer greater scope for linking EO data to biodiversity
(Nagendra 2001). Hence, there is often a need to translate LC/LU maps to those representing habitats with this undertaken through re-labelling and, where appropriate, merging of similar land cover classes (Lengyel et al. 2008) and, where needed, through integrating in situ data for habitat discrimination. Difficulties nevertheless arise because of different levels of definition and criteria used by specific classification systems. Morphological-structural and physio-ecological criteria are considered both in LC/ LU and habitat classifications, while phyto-sociological criteria tend to be emphasized in some habitat taxonomies. Commonly used classification systems dealing with $\mathrm{LC} / \mathrm{LU}$ or habitats also tend to be limited in their ability to map all aspects of the landscape and often do not contain the full diversity of LC/LU or habitat types. Furthermore, most were not designed to be compatible and hence lack interoperability between different LC/LU systems (Neumann et al. 2007; Herold et al. 2008) as well as between LC/LU and habitat taxonomies. A good LC/LU system should be able to describe with the same level of detail all relevant aspects of the earth surface and should well discriminate the concept of LC (biophysical attributes of the earth surface) from LU (the human intent applied to those attributes) (Turner et al. 2001).

As habitat mapping is increasingly required, partly in response to legal obligations, the majority of nations and regions have generated, as a minimum, maps of LC/LU using a range of classification schemes. The challenge, therefore, is to select the most useful LC/LU taxonomy for habitat mapping. Such taxonomy should also provide the best translation to a habitat taxonomy that is directly relevant to national and international reporting obligations. Thus, protocols are required to harmonize the different systems and standardize new and pre-existing products for long-term monitoring purposes (Boteva et al. 2004; Dimopoulos et al. 2005; Mücher et al. 2009; Bunce et al. 2010). Among the LC/LU taxonomies, the FAO land cover classification system (LCCS) (Di Gregorio and Jansen 1998, 2005) taxonomy was identified (Herold et al. 2008) as the most appropriate for providing a common language for translating and harmonizing different LC/LU legends, as recognized by the panel of the Global Observation of Forest and Land Cover Dynamics (GOFC-GOLD) (GOFCGOLD report n.20 2004). The main objective of this work is to investigate the potential of the FAO-LCCS 
for $\mathrm{LC} / \mathrm{LU}$ translation and mapping to a habitat classification system, in comparison to other commonly used LC/LU taxonomies, with the aim of facilitating biodiversity monitoring.

Based on five Natura 2000 sites in the Mediterranean countries of Italy and Greece, a qualitative analysis is carried out to identify the taxonomy able to provide the most effective framework to embed expert knowledge for $\mathrm{LC} / \mathrm{LU}$ to habitat translation and provide useful insights for EO data selection. In addition, a quantitative analysis, based on similarity and congruency measures, is carried out to complement (support) the qualitative findings. Finally, an application of the LC/LU to habitat mapping is provided for a Natura 2000 costal site.

This research was conducted within the three-year BIO_SOS (www.biosos.eu) project, funded within the European Union FP7-SPACE third call.

\section{Selection of LC/LU and habitat classification systems}

An overview of the most commonly used taxonomies for LC/LU and habitat mapping in European Countries is provided in this section (Table 1). The classification schemes for both habitats and land covers vary in the number and types of classes defined, in their implementation (hierarchical or otherwise), and in the features used for class definition. For mapping purposes, those taxonomies that can best describe the vegetation composition/structure should be preferred. These would also enable the monitoring of habitat qualitative features from the perspective of vegetation dynamics induced by global warming coupled with anthropogenic disturbances, which respectively determine species distribution shifts (Williams and Jackson 2007) and, either indirectly or directly the onset of successional processes, whose effects on physiognomy can be represented by this type of classification taxonomies. These effects might affect vegetation/animal community relations at the local scale and influence food webs and connectivity at the landscape level. A series of maps based on this kind of taxonomies might provide signals to managers to select among the range of possible options which are being proposed to adapt conservation to global changes (Heller and Zavaleta 2009).
Following the approach developed by Salafsky et al. (2003) for classifying threats, we assessed if classification systems were: (a) Hierarchical-Creates a logical way of grouping classes; (b) Comprehensive - Covers all possible objects on the scene by a class label; (c) Consistent_-All entries at a given level of the taxonomy are of the same type; (d) Expandable-New classes can be added without changing the full hierarchy; (e) Exclusive-Any given "object" can only be placed in one position within the hierarchy; (f) Geographically invariant-The labeling of a same object is invariant across different locations (see Table 1). For mapping purpose, systems meeting all these criteria are relevant to ensure a full coverage of the landscape and avoid uncertainty in describing objects. Criteria (b) and (d) are particularly useful in ecological studies for site management purposes. As an example, some habitat taxonomies do not include anthropic habitats or threatened vegetation types of ecological importance for species conservation in some geographical areas (e.g. Mediterranean).

The FAO-LCCS satisfies all criteria listed above. In LCCS, a land cover class is defined by the combination of a set of independent diagnostic criteria, termed "classifiers", hierarchically arranged. Since the set of criteria can be indefinitely enlarged, LCCS is an open (expandable) classification system with a virtually infinite amount of mutually exclusive classes. The classification in LCCS has two main phases: (1) the Dichotomous phase, where a dichotomous key, based on three classifiers (i.e., presence of vegetation, edaphic conditions and artificiality of cover), is used to define eight major land cover types; (2) the Modular-Hierarchical phase, where a combination of a predefined set of classifiers allows the definition of more detailed land cover classes. In each set, the classifiers are divided into three groups: (a) "pure land cover" classifiers; (b) "environmental" attributes; (c) "specific technical" attributes (Di Gregorio and Jansen 1998, 2005).

A software program (http://www.africover.org/ software_down.htm) has been developed to provide a step-by-step guide to defining classes within LCCS. Each land cover class is described by three elements: (a) a Boolean formula, consisting of a string of classifiers used for class definition (e.g. A12/A2.A5. A11.B4-A12.B1, that is "natural terrestrial vegetated/ open((70-60)-40\%) tall herbaceous forbs"); (b) the name of the land cover class (e.g. "Open annual short 


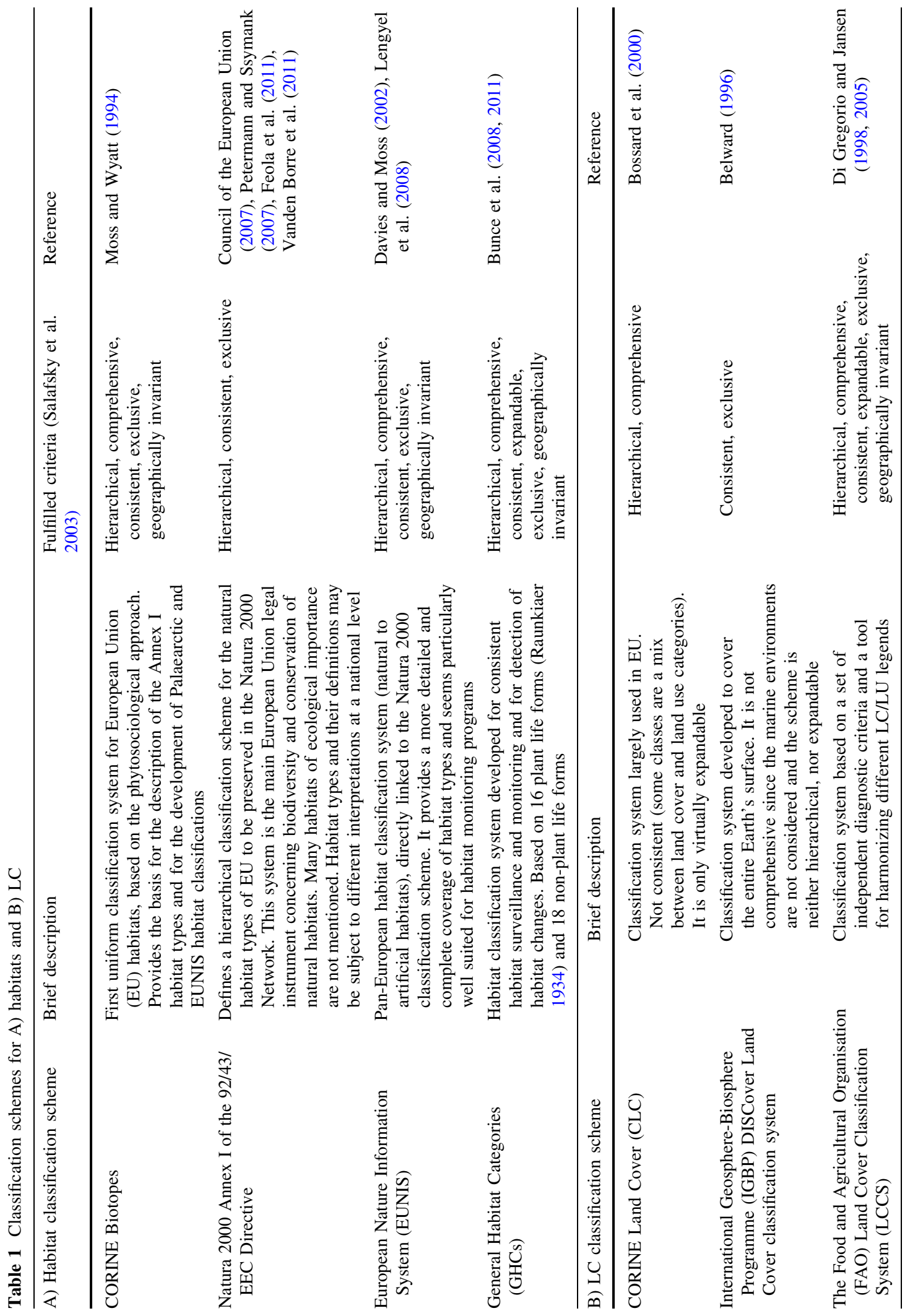


herbaceous vegetation on temporarily flooded land"); and (c) a numerical (GIS-friendly) code (http://www. africover.org/LCCS_hierarchical.htm).

\section{Materials and methods for qualitative and quantitative analysis}

Five sites belonging to the Natura 2000 Network were used in this study, with two being in Italy and three in
Greece (see Fig. 1). Pre-existing LC/LU, habitat and vegetation maps realized at a scale of 1:5,000 through visual interpretation of digital panchromatic orthophotos and validated by field surveys were used. During in-field campaigns, ancillary data on vegetation composition and structure, crop cover and type, stratification, land use and management, soil and site (e.g. aspect and slope) and water salinity, were collected, geocoded by a GPS and integrated into a GIS geodatabase using ArcGIS 9.2.
Fig. 1 Study sites location map within the context of EU 27 Natura 2000 Network and Biogeographical regions. For each site BIO_SOS code, Natura 2000 codes and SCI area are reported

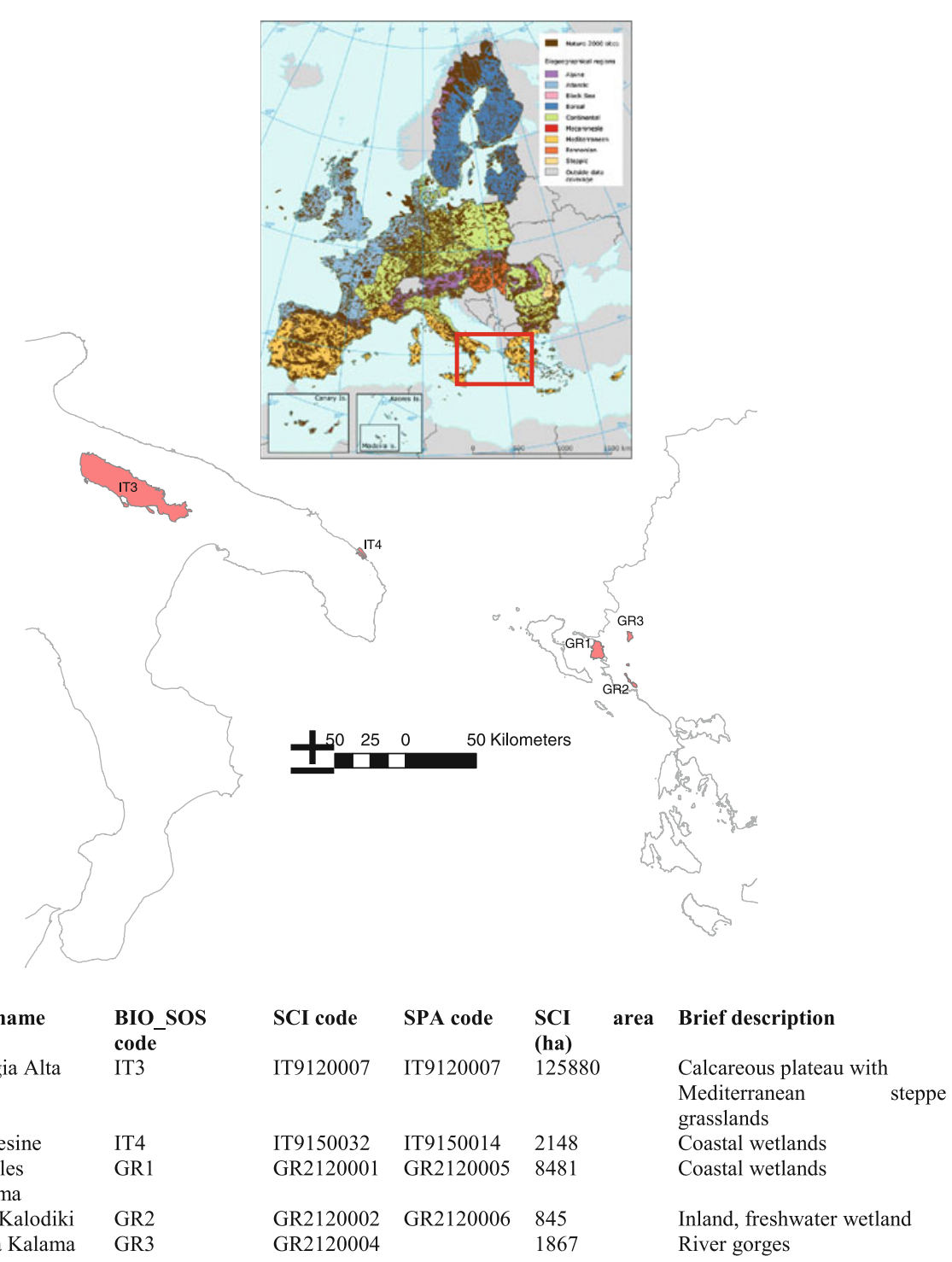


Based on expert knowledge from practitioner botanists, ecologists and EO data processing experts, the relationships between LC/LU (LCCS; CLC; IGBP) and habitat domains (Annex I, EUNIS, CORINE Biotopes) were determined. Expert knowledge was used to identify and fill the gaps (Perera et al. 2012) between the two domains and to integrate, where needed, in-field data for converting LC/LU into habitat classes.

In each site, a pre-existing vegetation map was used as reference map to define the labels of natural and semi-natural class types and find appropriate relationships between different taxonomies, whilst the LC/LU map, derived from photo interpretation, was used as reference map for labelling of artificial/agricultural types. Ancillary data were integrated where needed. To each patch of the appropriate reference map was assigned a set of labels, each corresponding to a specific category within a taxonomy. The rules defined in the user's manual of the taxonomies listed in Table 1 were strictly applied. LC/LU classes were assigned considering CLC at Level III and LCCS at Level II and Level III of the Modular-Hierarchical phase for terrestrial and aquatic/flooded classes, respectively. Habitat types were assigned according to EUNIS, Annex I, CORINE Biotopes at Level III, and GHC at Level III (no qualifiers). GHC categories were identified by using the key to Annex I (Bunce et al. 2010) and the EBONE handbook (Bunce et al. 2011). This information was arranged in a look up table, to enable a qualitative review and quantitative analyses aiming at analysing the relationships between LC/LU to identify the LC/LU taxonomy most suitable for habitat mapping.

Regarding the quantitative comparison of taxonomies, several studies have recently contributed to define a frame where the interoperability between taxonomies is assessed by introducing some semantic similarity measures of the different classification schemes (Ahlqvist 2004, 2005, 2008; Feng and Flewelling 2004; Fritz and See 2008). In those studies, the comparison was performed class by class by building a suitable semantic representation out of the definition of each class, in each of the taxonomies to be compared. In contrast to these approaches, the quantitative analysis proposed in this paper does not focus on class definitions but aims at somehow measuring the congruency of the results of different taxonomies being applied at the given selection of sample sites.
The approach is conceptual and is not related to either spatial or semantic properties.

To start with, the Jaccard's Similarity Index for each pair of sites was calculated (for the five sites studied, there are ten possible pairwise comparisons). The index reflects the overlap in the landscape composition between the two sites. More specifically, when comparing two sites, the number of LC/LU classes they have in common was recorded in both sites. This number was then divided by the total number of classes observed. Jaccards value ranges from 0 when the two sites have no common LC/LU classes to 1 when both sites have exactly the same landscape composition. This index evidences only the presence of classes and not their coverage. For any given pair of sites, this was repeated for each taxonomy.

Once all the pairwise comparisons were performed, for each taxonomy the resulting ten values of similarity, one for each pair of sites, allowed the ranking of all site pairs according to their similarity, from more similar to less similar. If the taxonomies produced congruent comparisons then these rankings should coincide. In order to test for this congruence among taxonomies a numerical estimator of the "distance" among taxonomies was introduced. The "distance" metric adopted compares two taxonomies by contrasting the two rankings produced. Specifically, the index is calculated as the number of pair exchanges needed to make the two rankings identical. Given the length $N$ of the rankings ( $N=10$ in our case) the distance ranges from 0 , when the rankings are identical, to the maximum value $N ! /(2 *(N-2) !)$, which corresponds to the distance between a sequence of 10 numbers ordered increasingly, and the same sequence in the reversal order. As the number of exchanges increases this means that the taxonomies are less similar. By simulations it was verified that this "distance" index satisfies the properties of a metric.

Finally, a LC/LU to habitat mapping application to a Natura 2000 costal study site, Le Cesine, in Italy (IT4) was carried out based on the findings of the qualitative analysis and the pre-existing thematic layers (Tomaselli et al. 2012) available for the site (i.e., LC/LU and in situ data on lithology, soil surface and subsurface, water quality), as described further in the next section. The algorithm for LC/LU to habitat mapping was realized within eCognition 8.7 (www. ecognition.com) environment and Decision Tables (DTs) were used to describe the complex relationships 
involved in the mapping. DTs correspond to a formalism widely used in software engineering to describe complex relations among predicates and actions (Fisher 1966). DTs have proven to be easier to understand and review than code, and have been successfully used to produce specifications of complex systems and their decision trees (Pooch 1974). It is important to note that auxiliary software tools can also be used to create, validate and process DTs (e.g. LogicGem by Catalyst Corp.). A decision table summarizes the action to be taken depending on the values of conditions that exist at the time the decision table is consulted. DTs override system flow charts in more complex circumstances, particularly those where several criteria determine an action demanding more specialized models. A typical decision table is divided into 4 parts: (1) a condition stub-which shows the conditions that determine which actions will result; (2) condition entries are the combination of conditions expressed as rules; (3) an action stub which contains the possible actions which can occur as a result of the different condition combinations; (4) action entries containing the action to be taken.

In DTs, conditions are expressed as questions that may be answered by Yes/No responses. The condition entries are then specified as combinations of these responses. The relevant action for each combination of conditions is recorded by an $\mathrm{X}$ in the action stub (see next section).

\section{Results and discussion}

Table 2 links the different $\mathrm{LC}$ and habitat taxonomies at the maximum level of detail, allowing both qualitative comparison and quantitative analysis between the schemes.

A qualitative review of habitat and $\mathrm{LC} / \mathrm{LU}$ taxonomies

\section{Habitat taxonomies: Annex I and EUNIS}

The comparison of the different habitat legends highlighted several omissions in the Annex I scheme with respect to EUNIS, for the sites considered (Table 2), namely: (a) different shrub vegetation types of high conservation value; (b) nitrophilous and subnitrophilous (subject to grazing) grasslands that are often functionally linked to Annex I habitat types (e.g., habitat type 6220*); (c) reeds and sedges communities, as already highlighted by Petermann and Ssymank (2007). In other cases, Annex I habitat types are not well defined, such as habitat $6220^{*}$ _ "Pseudosteppe with grasses and annuals of the TheroBrachypodietea", which contains either annual or perennial communities.

\section{Habitat taxonomies: Annex I and GHCs}

The correspondence between Annex I habitat types and GHCs was not always unique, with the same habitat assigned, in some cases, to several GHCs depending upon local conditions and conservation status. As an example, habitat 6220* in GHC can refer either to Caespitose hemicryptophytes (CHE) or to Leafy hemicryptophytes/Caespitose hemicryptophytes (LHE/CHE) if located in natural environments, or to the category Urban (herbaceous) (URB(GRA)) if falling within managed areas. However, to identify a specific habitat type, GHC methodology provides additional environmental, site, management and other qualifiers (Bunce et al. 2011) to be selected on the basis of expert knowledge.

\section{LCCS and CLC taxonomies with respect to Annex I}

A certain level of disagreement between the LCCS and CLC is well documented in the literature (Jansen and Di Gregorio 2002; Neumann et al. 2007; Herold et al. 2008), especially when considering those CLC classes that represent land cover complexes, or that are defined by using a mix of LC and LU criteria, and particularly for those that are regarded as artificial or managed (e.g., agriculture) categories or where there is uncertainty as to whether these are "natural" or "managed", as evidenced in Table 3 (Bossard et al. 2000; Di Gregorio and Jansen 2005). A further limitation of CLC in describing natural and seminatural vegetated environments is that class descriptions have a very broad meaning. Within each coarse vegetated class, a number of habitats occur. As an example from Table 2, CLC class 4.2.1 "salt marshes" (second column) can be associated to six habitats including 1310, 1410, 1420, 7210 (Annex I, third column) and $\mathrm{A} 2.53 \mathrm{C}$ and $\mathrm{A} 2.53 \mathrm{D}$ (Eunis, fifth column). This means that one-to-many LC/LU to habitats relations occur and hence the CLC system 


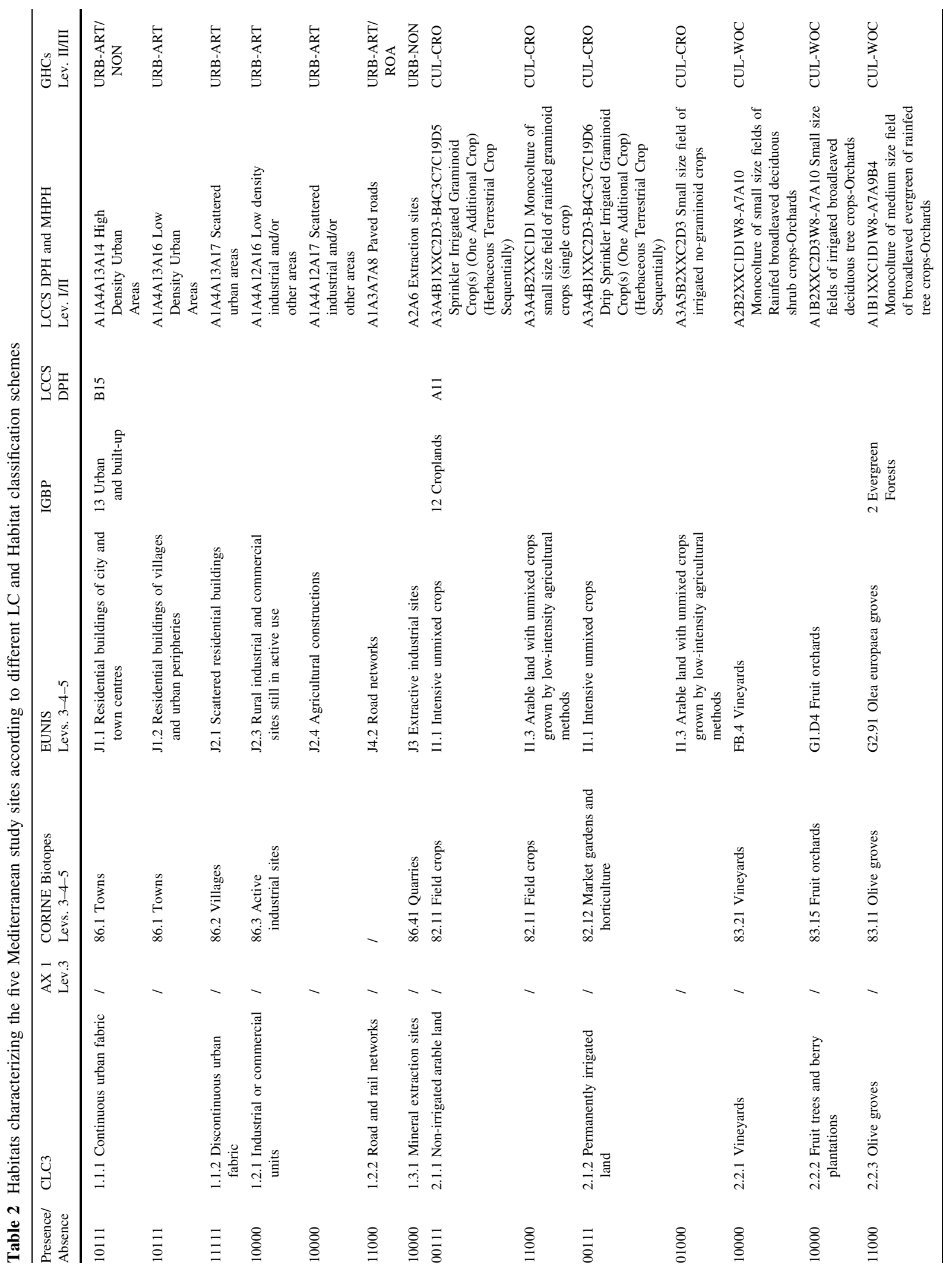




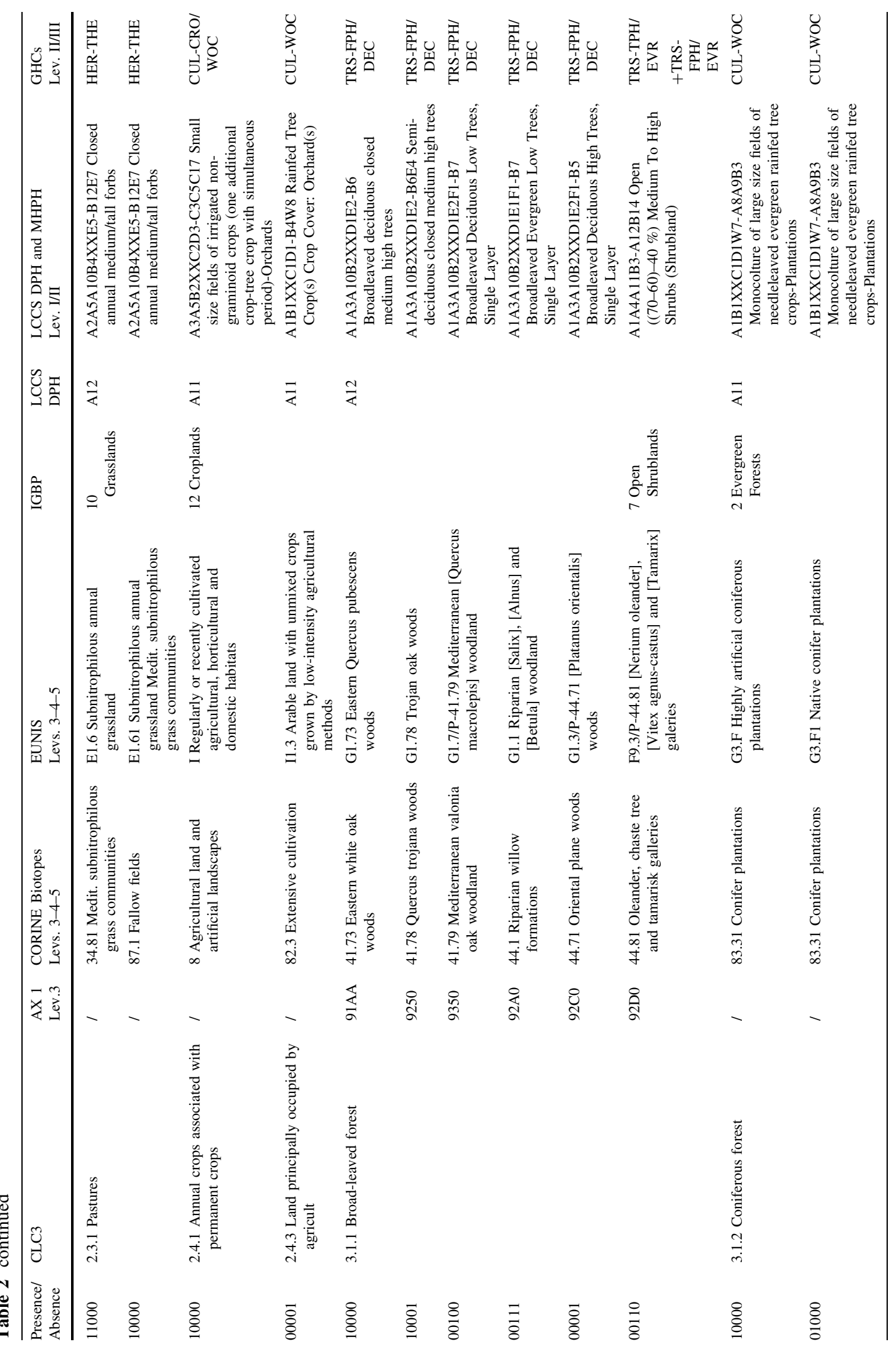




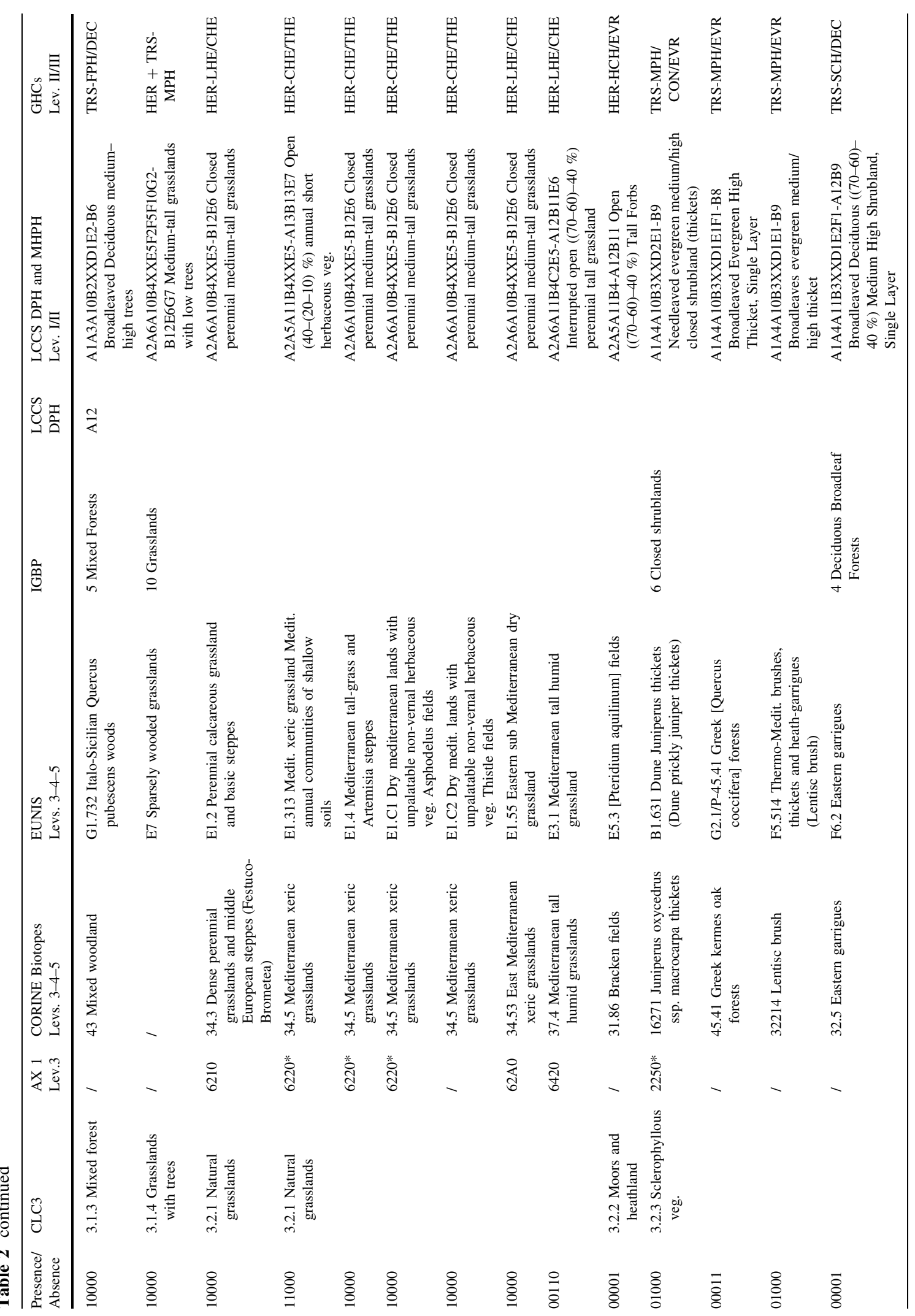




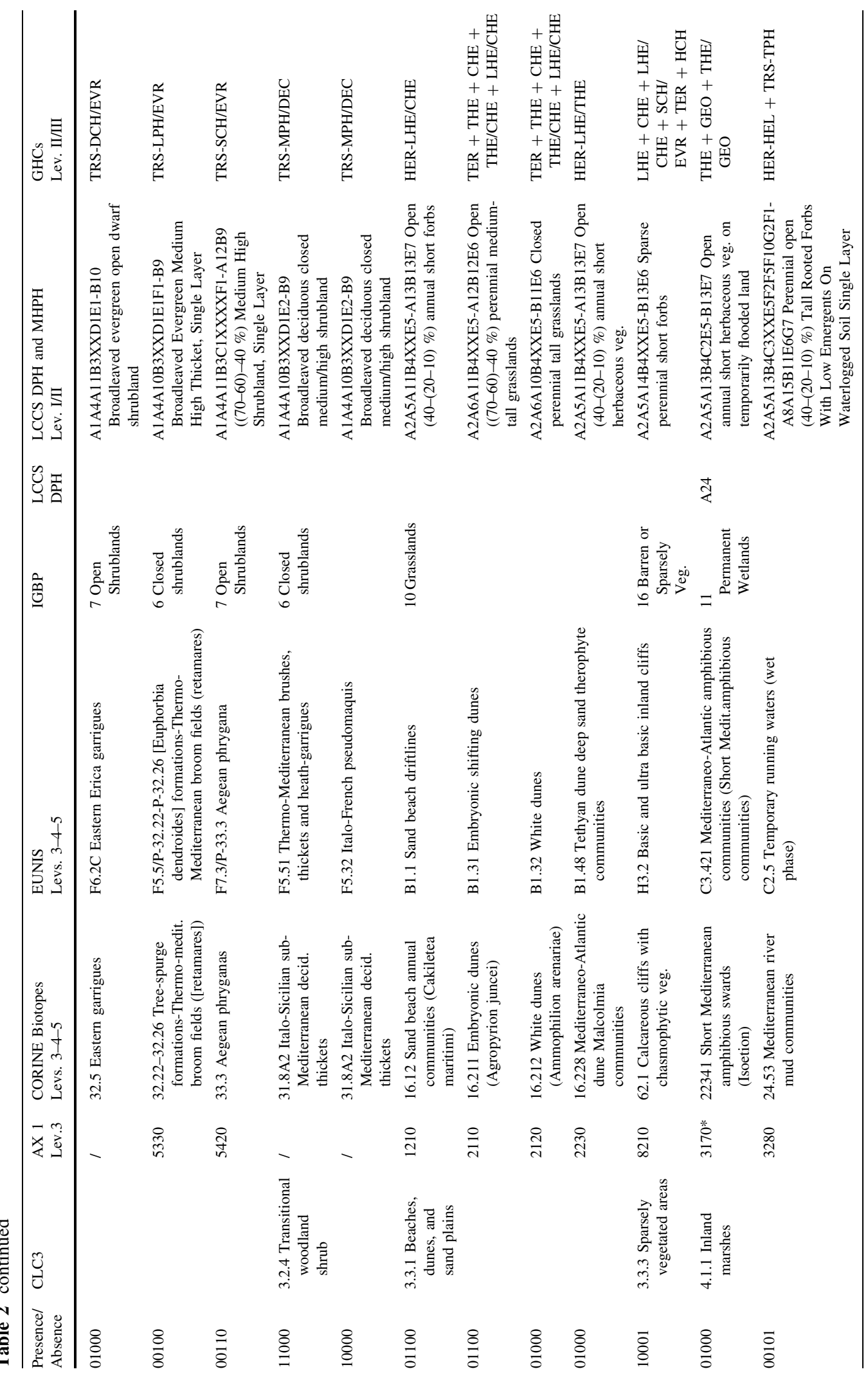




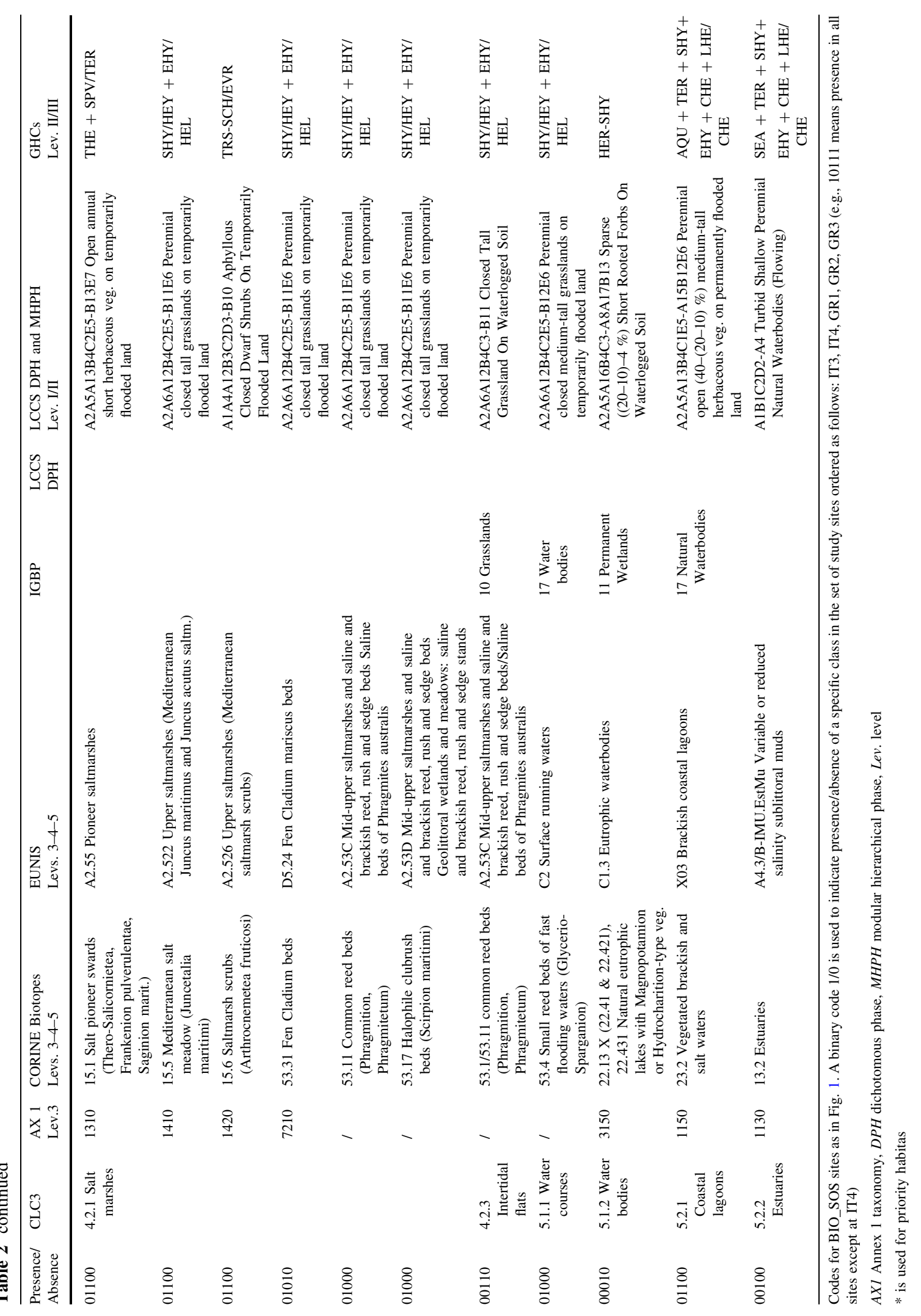




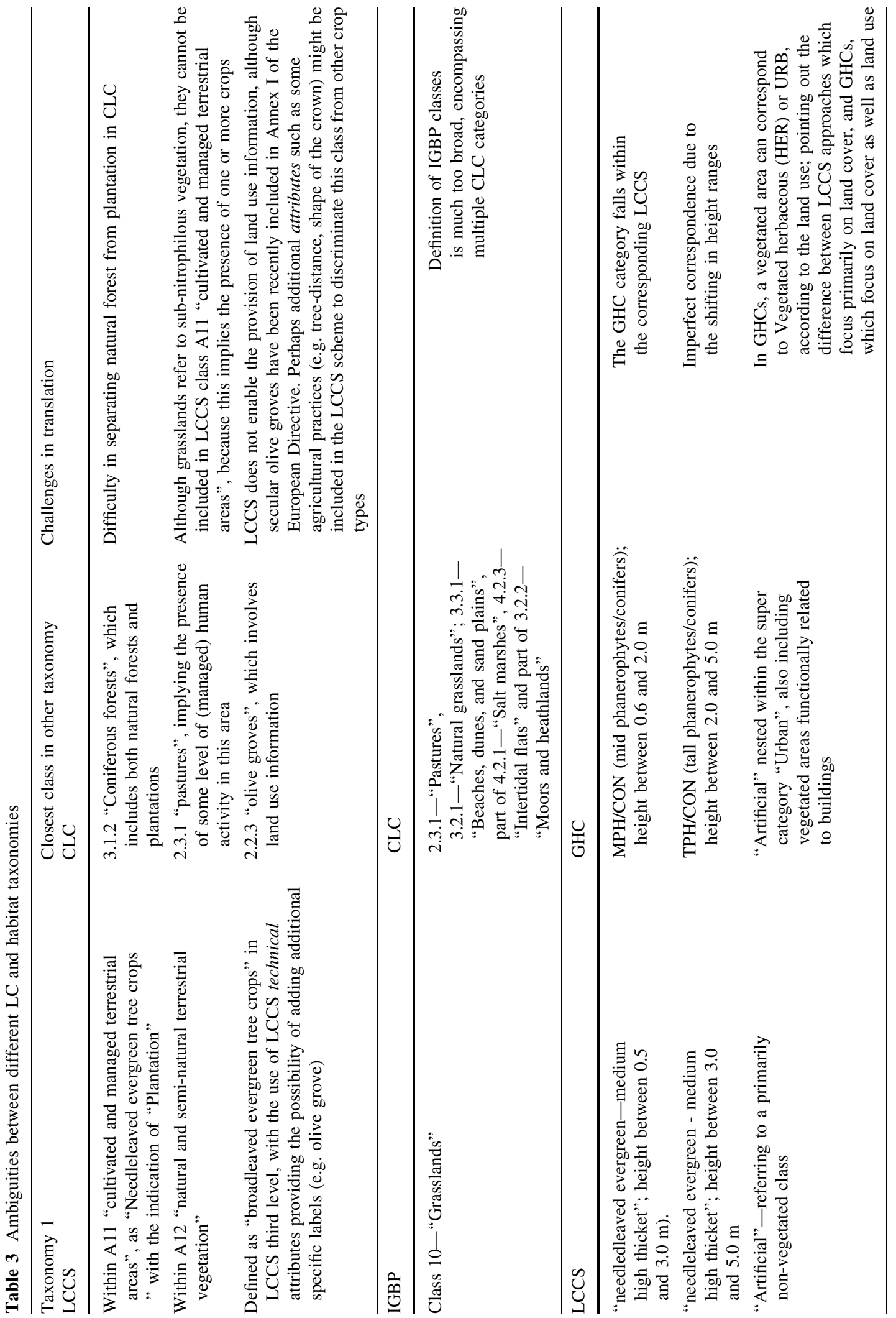


does not provide a useful framework for fine-grain habitat mapping. Consequently, any monitoring activity based on such a taxonomic scheme is unlikely to differentiate changes in habitat composition, connectivity and disturbances over short periods of time. Compared to the CLC, LCCS provides a higher level of detail as many different "pure" land cover classifiers can be used for class discrimination (Tomaselli et al. 2011). In Table 2 (eighth column), two different LCCS class codes are associated to two different habitats (i.e., 1310, 1420) in one-to-one relations. The remaining four (i.e., 1420, 7210, A2.53C and A2.53D) of six habitats associated to CLC 4.2.1 are still linked to the same LCCS class code (i.e., A24/A2.A6.A12. B4.C2.E5-B11.E6 "aquatic perennial closed tall grassland on temporarily flooded land"). Nevertheless such ambiguity can be solved by combining environmental attributes, such as lithology, soils, landform and water quality, with the "pure" classifiers of the modular hierarchical phase, as evidenced in Table 4, where habitats 1410 and $\mathrm{A} 2.53 \mathrm{D}$ have been distinguished from the pair 7210 and $\mathrm{A} 2.53 \mathrm{C}$, with these still not separable. For Le Cesine (IT4) site, Table 4 evidences how the use of LCCS environmental attributes can solve the ambiguity of most LC/LU classes to habitat transitions up to the level of habitats and one-to-one class relationships can be found. Figure 2 offers a visual description of LCCS potentialities in terms of both its finer habitat discrimination with respect to CLC (Fig. 2a) and detection of "within" class changes related to a specific class modification (Fig. 2b). Within LCCS, specific floristic attributes can also be added to complete habitat class description. However this attribute cannot be considered for habitat mapping since it cannot be easily detected from EO data, mainly when EO hyper-spectral data are not available (Nagendra 2001).

Concerning LC/LU and subsequent habitat mapping from VHR EO data, multi-temporal (seasonal) and/or context-sensitive information is generally required for improving classification (Bruzzone et al. 2004; Amoruso et al. 2009). If only one date is analysed, due to the limited number of available spectral bands (e.g., 4 in IKONOS and QuickBird) different objects of the scene can have similar spectral signatures in the image even if fine spatial details of the landscape can be detected in a VHR image. Consequently, an appropriate selection of multi-seasonal images should be carried out before any classification. To do this, expert knowledge elicitation of the most useful features for class discrimination (e.g. the different periods of maximum biomass and plant development for terrestrial vegetated classes (A12); the different months of flooding period for the aquatic or regularly flooded vegetated classes (A24) or specific agricultural practices to differentiate crops within cultivated classes (A11)) is recommended. Such information should be embedded within the LCCS framework for the improvement of LC/LU classification and subsequent habitat mapping. In this paper, Table 4, in the column labelled "additional expert prior information", reports the information useful for the selection of an appropriate minimum (for cost optimization) set of a multi-temporal EO image set for class discrimination in the IT4 site.

\section{IGBP and CLC with respect to Annex I habitats}

With regards to IGBP and CLC, as already evidenced in Herold et al. (2008), general weaknesses and inconsistencies of the IGBP class set are provided mainly by thresholds in height and cover, when considering forest definition, and the poor and coarse definition of class 11 (wetlands). In this specific case, 17 LC classes are too few and coarse to achieve the discrimination of detailed and fine classes such as habitat types (see Table 4 for further details). This is a logical consequence of the fact that IGBP has been designed for the detection of LC types at a global level and large scale (Herold et al. 2008; Tchuenté et al. 2011) and is not best suited for habitat classification and monitoring at the scale of individual protected areas.

\section{LCCS and GHG habitats}

Habitats, as defined in (Bunce et al. 2011), can be considered "as an ecological refinement of the land cover categorisation as developed by FAO in the LCCS". GHCs contain information about life form, height, leaf type and cycle. Therefore, LCCS classes as defined by means of pure classifiers (including life form, height, leaf type and cycle) can provide a good match with GHCs. However, some discrepancies between the two systems can be highlighted. This is the case of ranges and thresholds in height defined by GHC for chamaephytes and phanerophytes which do not correspond exactly to those defined by LCCS for trees and shrubs. In addition, LCCS defines different 


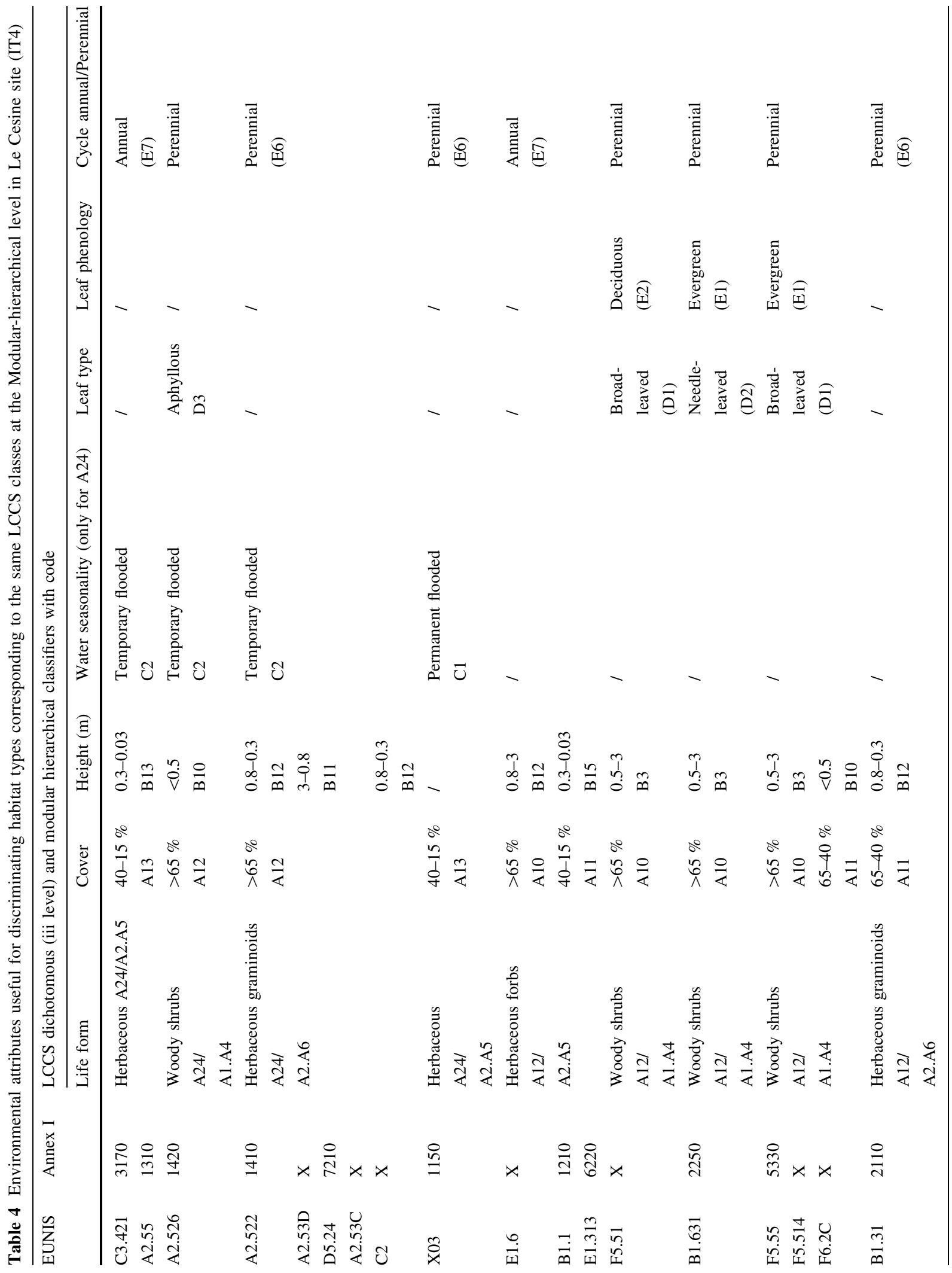




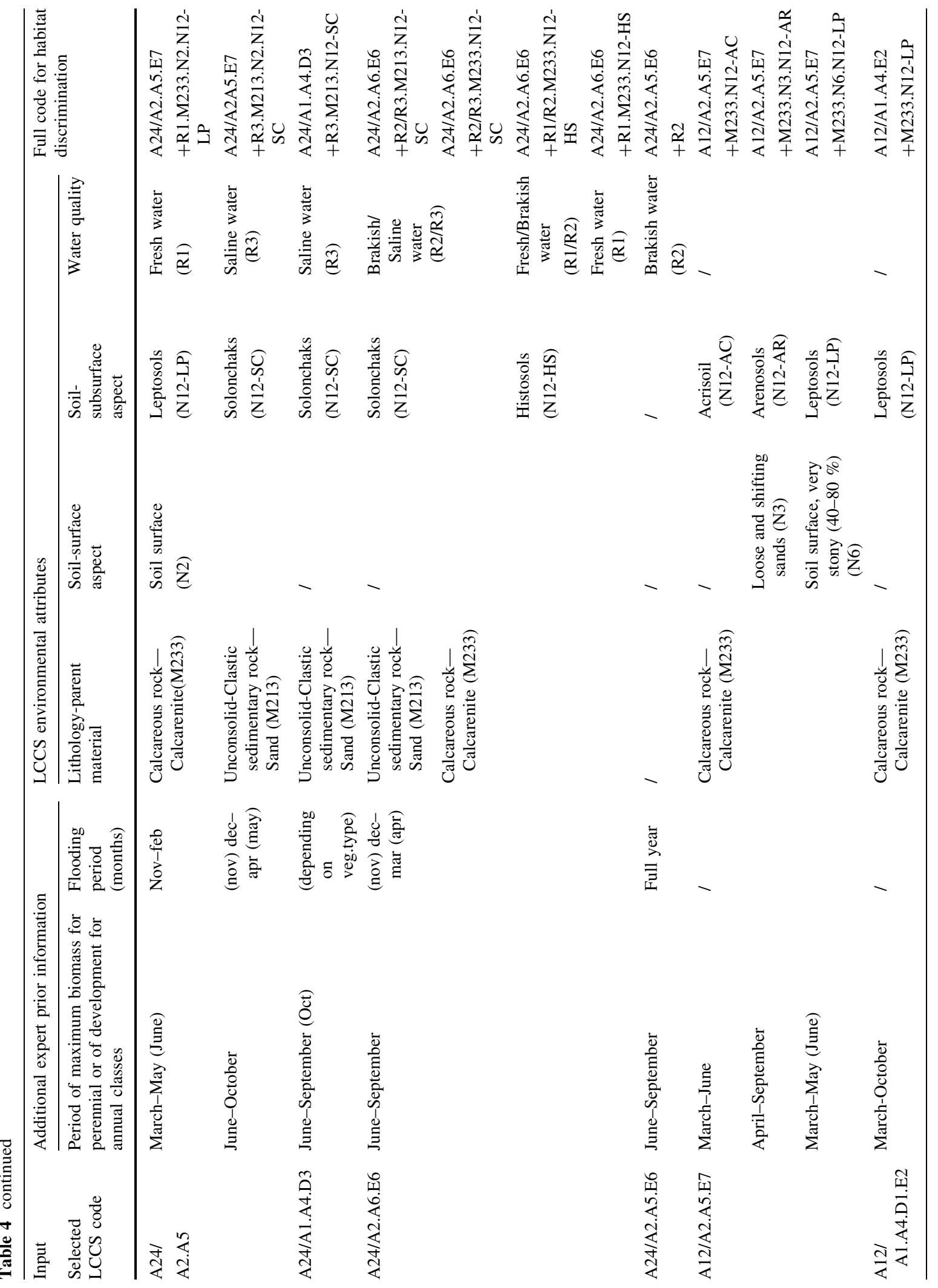




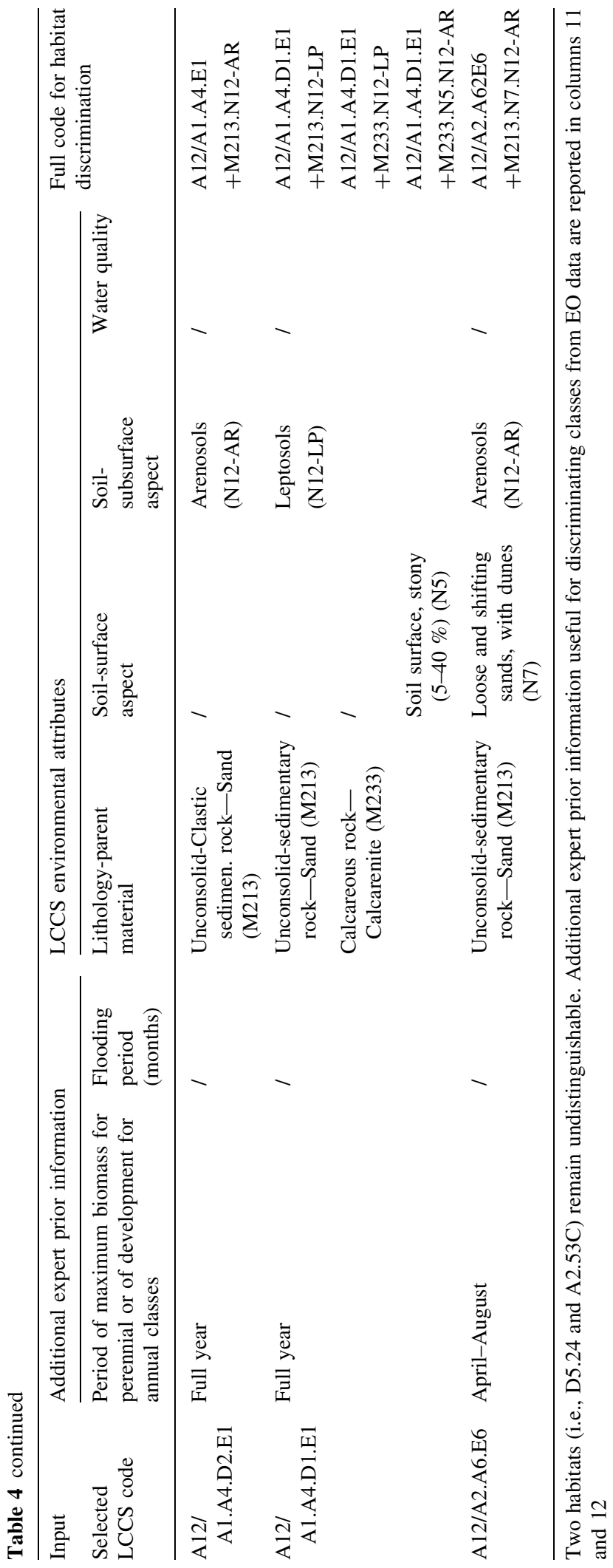


ranges of height for herbaceous types, whereas these ranges are not provided in GHC (Kosmidou et al. 2012). Table 3 provides further details. A critical difference between LCCS and GHCs lies in the definition of the "Artificial" categories. In LCCS "Artificial" is a primarily non vegetated class. In GHC, "Artificial" falls within the super category "Urban", applying to buildings or land functionally related to buildings, which includes vegetated areas. Hence a vegetated area can fall in vegetated Herbaceous (HER) or in Urban (URB), according to the land use, and have a different ecological value.

Quantitative analysis: similarity measure and distance matrix

With respect to the sites, the overall greatest similarity measured by the Jaccard's index is observed between sites GR1 and GR2 (Table 5) (i.e., two similar environments belonging to the same country, Greece). The same result holds in all the classification systems, except in Annex I; that is probably due to the exclusion of all the artificial and certain semi-natural habitat types in the Annex I classification. Similarity in artificial and semi-natural class types implies similarity in human practices, usually more homogeneous in the same country than in different ones. Contrarily, the most similar sites, according to Annex I, are GR1 and IT4, which contain the higher percentage of natural (Annex I) classes, 70 and $48 \%$, respectively. Focusing on the classification systems, the highest values, ranging from 0.454 to 0.875 are the ones obtained by IGBP, due to the few and coarse classes that result in an artificial high number of overlaps. EUNIS, CORINE Biotopes and LCCS show low values on average, and also quite similar ranges (EUNIS from 0.057 to 0.409; CORINE Biotopes from 0.081 to 0.409 ; LCCS from 0.031 to 0.500). EUNIS and CORINE Biotopes are closely related classification systems and that justifies the results. As stated, LCCS provides a very flexible tool, permitting class definitions to be enriched by adding further attributes. The detailed level of class description yields a better discrimination and a reduced number of co-occurrences in the site composition. Annex I also arises from CORINE Biotopes, but the results are quite different due to the emphasis of Annex I on natural habitat types, leading to results that emphasize the similarity in composition of natural habitats of high biological value. Thus, the Jaccard's index values applied to Annex I are in strongest disagreement with those for other systems. Moreover, when considering the Annex I data set, the best score is obtained by IT4 with GR1, both coastal wetlands, and by GR3 with IT3 (probably due to the presence and dominance of woody habitat types in both these sites). On the other hand, the high similarity values of the pairs GR1-GR2 and GR2-GR3, within the majority of the taxonomies may be due to common practices of management of semi-natural and artificial areas.

The results of the similarity measure on the given dataset are then used to build up a distance matrix for a selection of taxonomies, the ones allowing for a satisfactorily detailed description of classes (thus excluding IGBP), as shown in Table 5b. The selected taxonomies are hierarchical in structure: for three of them (LCCS, EUNIS, GHCs) the classes are defined through a pre-selected set of classifiers/criteria/ attributes; moreover all but Annex I include "human" classes. The comparison of habitat taxonomies always generates small distance values and suggests a similar behaviour. Annex I turns out to be the "least similar" taxonomy with respect to all the remaining habitat taxonomies, possibly due to the lack of "artificial" classes in this classification scheme. On the other hand, the comparison of LCCS and CLC3 exhibit the highest distance, confirming that a conversion from one LC taxonomy to the other should be handled with care due to the many-to-many relationships between the two classification schemes. A reason for such differences in behaviour might rely on the discrimination of primarily vegetated from non-vegetated areas, which is done at the top of the hierarchy in LCCS, thus determining a mismatch from the very beginning of the descent along the branches of the taxonomic trees. However, the congruency of the two systems is improved if environmental attributes are added to the LCCS classification. This trend is reproduced for the comparison of LCCS with all other taxonomies. About the comparison of Land Cover and Habitat taxonomies, a good match would be expected for taxonomies used in related projects such as CLC and Corine Biotopes and the measured distance confirms it. However the best results in the comparison are the ones obtained by LCCS with the addition of the environmental attributes, which turns out to have the overall lowest distances to almost all habitat taxonomies but Annex I. The highest similarity is obtained 
(a)

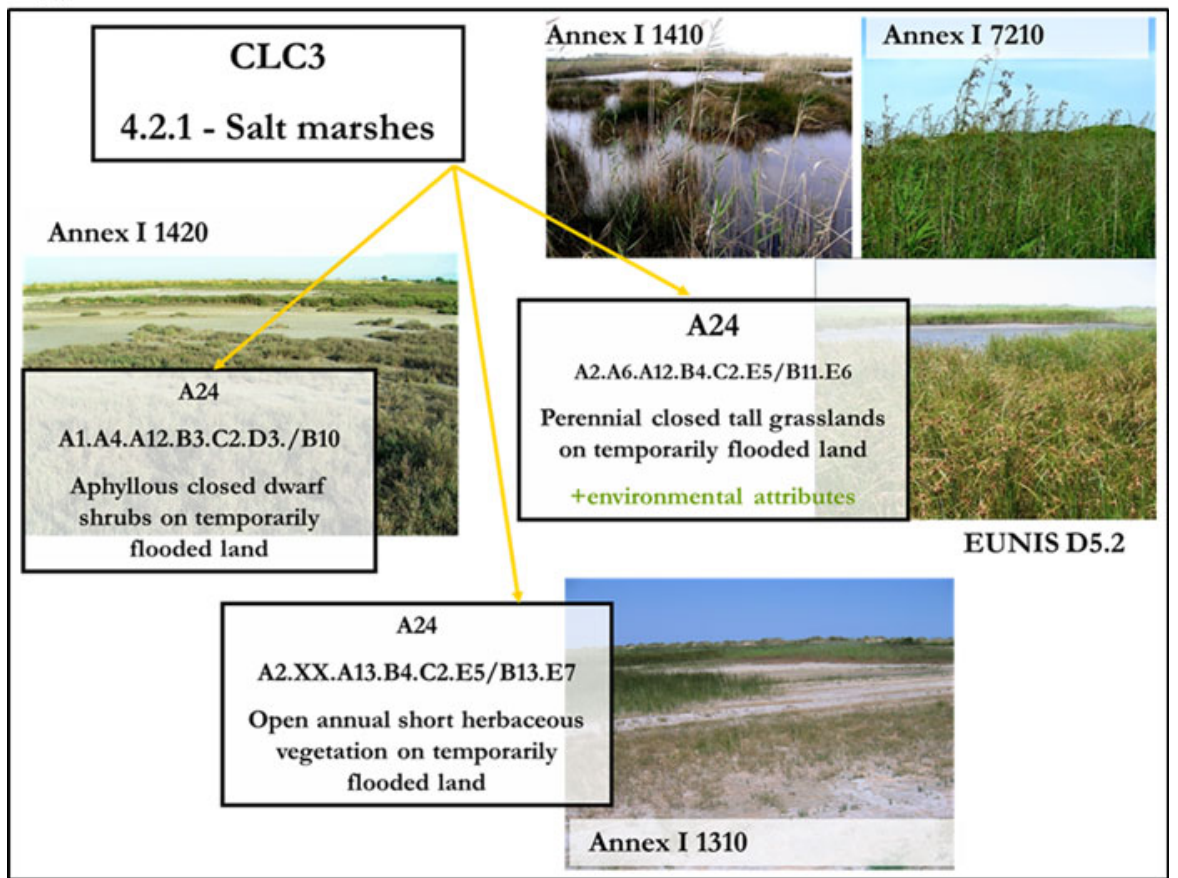

(b)

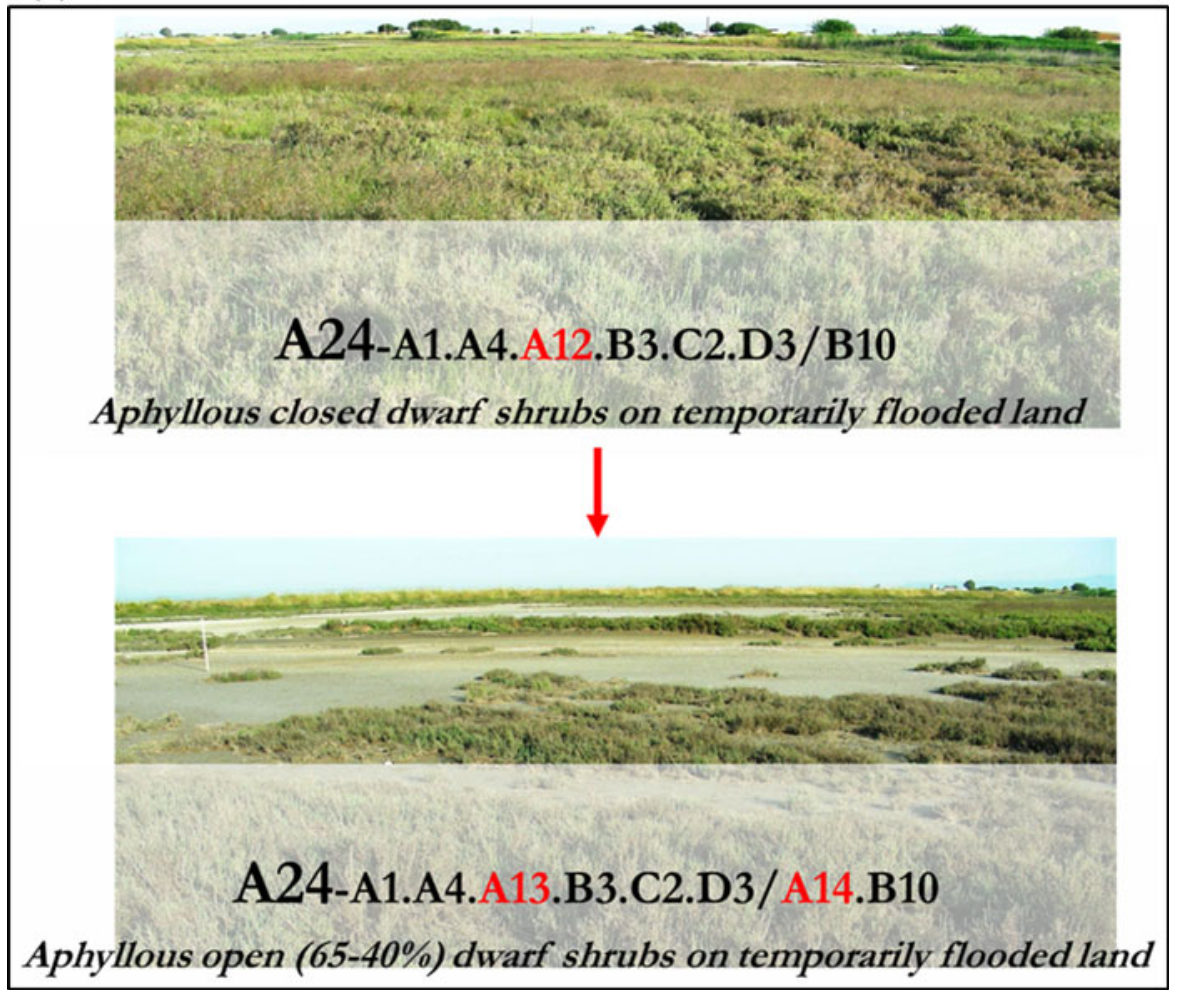

Fig. 2 a The translation of LC class salt marshes from CLC taxonomy into LCCS taxonomy can identify 5 different habitats on the basis of land cover classifiers and additional environmental attributes, b LCCS legend can describe within class changes due to specific class modification as in the example reported in this figure 
for the coupling EUNIS-LCCS when the environmental attributes are taken into account. Regarding GHCs, the rule based system in (Bunce et al. 2010) has been used to assign Level II/III classes, starting from the Annex I classification, which actually represents the best match. However, since the classification has been stopped at the first level, it can be expected that a further refinement of the classification would give more detailed results, and thus greater similarity especially when compared to LCCS, which shares with GHCs similar building rules. As a conclusion, this numerical test based on a small data set confirms what was expected from the qualitative reasoning about the main characteristics of the systems.

LC to habitat mapping in Le Cesine Natura 2000 site (IT4)

The effort to translate between LC/LU and habitat mapping was based on (a) the pre-existing LC/LU map (Fig. 3a) and the additional thematic maps (i.e., lithology, soil surface aspect and soil subsurface aspect, water quality obtained by in-field campaigns) which, layered into a GIS (Fig. 3b), were used as inputs of the mapping process and (b) the expertknowledge elicited in Table 4 and coded as decision rules in the Decision Table shown in Table 6.

The input LC/LU classes are: nine (semi) natural LCCS classes represented by the subset LCCS code elements reported in Table 4, column labeled as "input"; three additional cultivated (A11) classes (i.e., no-graminoid crops, coniferous plantation and olive groves) and two artificial (B15) categories (i.e., paved roads and scattered urban areas). The full LCCS class dichotomous and hierarchical codes are provided in Fig. 3a in the LC/LU map legend. The code components corresponding to cover density and height classifiers were not considered in the mapping process, as already discussed in the previous section and evidenced in Table 4. Eighteen output habitats are expected for this site (see columns "Annex I" and/or "Eunis" in Table 4). The habitats were reported in the "action entries" section of Table 6, which includes also the corresponding plant species explicated in the LCCS technical attribute. Nevertheless, this attribute was not used in the mapping process which is mainly

Table 5 Jaccard's Similarity Index values calculated for the pairwise comparison of all the studied sites

\begin{tabular}{|c|c|c|c|c|c|c|c|c|c|}
\hline \multirow{2}{*}{$\begin{array}{l}\begin{array}{l}\text { Pair of } \\
\text { sites }\end{array} \\
\text { IT3-IT4 }\end{array}$} & \multirow{2}{*}{$\begin{array}{l}\text { IGBP } \\
0.4545\end{array}$} & \multirow{2}{*}{$\begin{array}{l}\text { CLC3 } \\
0.3200\end{array}$} & \multirow{2}{*}{$\begin{array}{l}\text { LCCS-MHP } \\
\text { Lev. II/III } \\
0.1351\end{array}$} & \multicolumn{2}{|c|}{$\begin{array}{l}\text { LCCS }+ \text { environmental } \\
\text { attributes }\end{array}$} & \multirow{2}{*}{$\begin{array}{l}\text { CORINE biotopes } \\
\text { Levs. } 3-4-5 \\
0.2105\end{array}$} & \multirow{2}{*}{$\begin{array}{l}\text { ANNEX } 1 \\
\text { Level } 3\end{array}$} & \multirow{2}{*}{$\begin{array}{l}\text { EUNIS } \\
\text { Levs. 3-4-5 } \\
0.1556\end{array}$} & \multirow{2}{*}{$\begin{array}{l}\begin{array}{l}\text { GHCs } \\
\text { Lev. II/III }\end{array} \\
0.3077\end{array}$} \\
\hline & & & & 0.1795 & & & & & \\
\hline IT3-GR1 & 0.4545 & 0.1923 & 0.0286 & 0.0750 & & 0.0811 & 0.0476 & 0.0682 & 0.2083 \\
\hline IT3-GR2 & 0.5000 & 0.2174 & 0.0270 & 0.0909 & & 0.1000 & 0.0769 & 0.0811 & 0.2500 \\
\hline IT3-GR3 & 0.6667 & 0.2174 & 0.1556 & 0.1563 & & 0.1724 & 0.3000 & 0.1714 & 0.3333 \\
\hline IT4-GR1 & 0.7778 & 0.4737 & 0.1389 & 0.1944 & & 0.2571 & 0.3333 & 0.2286 & 0.3462 \\
\hline IT4-GR2 & 0.6667 & 0.3158 & 0.0233 & 0.0588 & & 0.1212 & 0.1111 & 0.0909 & 0.2917 \\
\hline ITA-GR3 & 0.5000 & 0.2500 & 0.0263 & 0.0278 & & 0.1176 & 0.0556 & 0.0571 & 0.1538 \\
\hline GR1-GR2 & 0.8750 & 0.6429 & 0.4000 & 0.4348 & & 0.4091 & 0.2941 & 0.4091 & 0.4444 \\
\hline GR1-GR3 & 0.6667 & 0.4375 & 0.1923 & 0.2593 & & 0.2308 & 0.1667 & 0.2308 & 0.2500 \\
\hline \multirow[t]{2}{*}{ GR2-GR3 } & 0.7500 & 0.4286 & 0.2500 & 0.3500 & & 0.3158 & 0.1818 & 0.3158 & 0.3125 \\
\hline & & Corine & Biotopes & Annex I & EUNIS & GHC II/III & LCCS & \multicolumn{2}{|c|}{ LCCS + ENV. ATTR } \\
\hline & & 5 & & 10 & 9 & 11 & 14 & 10 & \\
\hline \multicolumn{2}{|c|}{ Corine Biotopes } & & & 7 & 4 & 8 & 9 & 5 & \\
\hline \multicolumn{2}{|l|}{ Annex I } & & & & 7 & 5 & 12 & 10 & \\
\hline \multicolumn{2}{|l|}{ EUNIS } & & & & & 6 & 5 & 3 & \\
\hline \multicolumn{2}{|l|}{ GHC II/III } & & & & & & 11 & 9 & \\
\hline \multicolumn{2}{|l|}{ LCCS } & & & & & & & 4 & \\
\hline
\end{tabular}

Abbreviations of BIO-SOS codes as in Fig. 1, b distances of taxonomies measured as pair wise exchanges separating the corresponding Jaccard's index rankings on the given sites dataset 
based on the contribution of the additional environmental attributes from in-field campaigns.

The LC/LU to habitat mapping was carried out based on the decision rules of Table 6 . Within each patch of the input LC/LU map, the labels of all GIS layers were combined as in the last column of Table 4 . Then the combination of True/False conditions in Decision Table 6 was checked. As a result, for each input LCCS class (entry), a habitat label was identified (action) and assigned to the corresponding patch of the output map. Figure 4 illustrates two examples related to the discrimination of some habitats already discussed in previous sections. Figure 5 shows the final output habitat map. As evidenced in Fig. $4 \mathrm{~b}$ and in Fig. 5, an ambiguity still remains between 7210 and

(a)
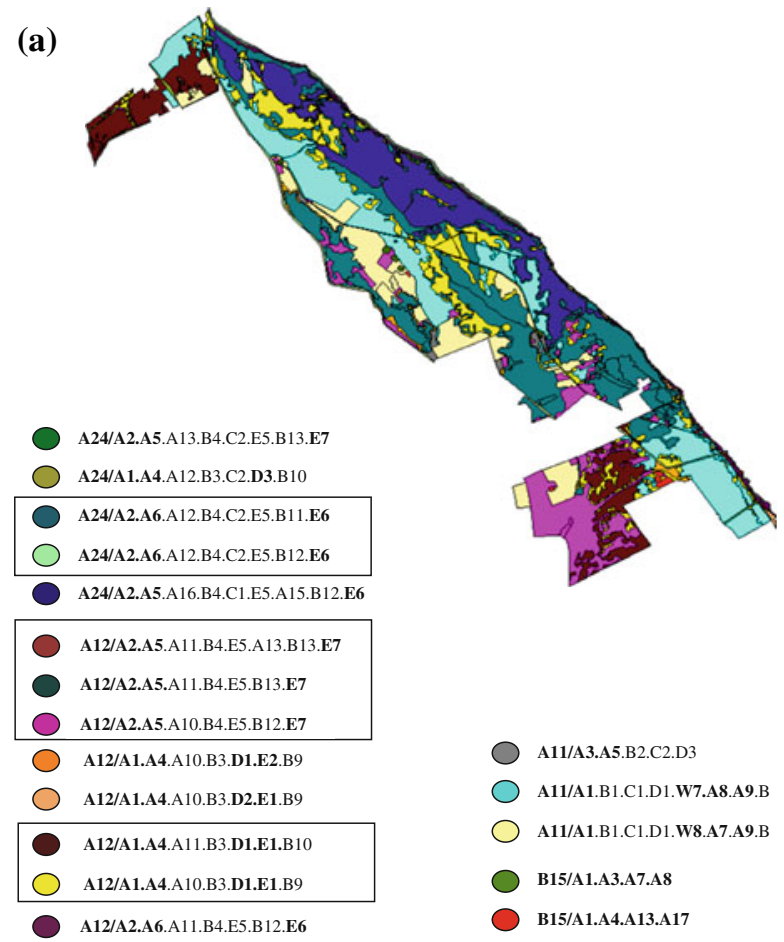

Fig. 3 a Pre-existing LC/LU map in LCCS taxonomy for Le Cesine site (IT4). The alphanumeric code components used for translating between LC/LU to habitat mapping are evidenced in bold and corresponds to the ones representing the dichotomous category (i.e., A12 natural and semi-natural terrestrial vegetated or A24 Natural and semi-natural aquatic vegetated), leaf type (D1 broadleaved, D2 needleaved, D3 aphyllous) and leaf phenology (E6 perennial or E7 annual). The rectangular boxes include LC/LU classes which are considered as a single input to the mapping algorithm because they have the same bold codes
EUNIS A2.53C habitats because they have the same environmental attributes.

The pre-existing habitat map from in-field campaign available for this site was used as reference map for validating the final habitat output map. The label of each patch in the output map was compared to the label of the corresponding patch in the reference map. A confusion matrix was generated to evaluate the mapping performance in terms of overall accuracy (OA) and error tolerance (Congalton and Green 2009) of the output map. The OA was obtained as the ratio of the number of patches in the output maps correctly assigned by the total number of patches considered. The resulting accuracy was $97 \%$ with an error tolerance of $0.02 \%$.

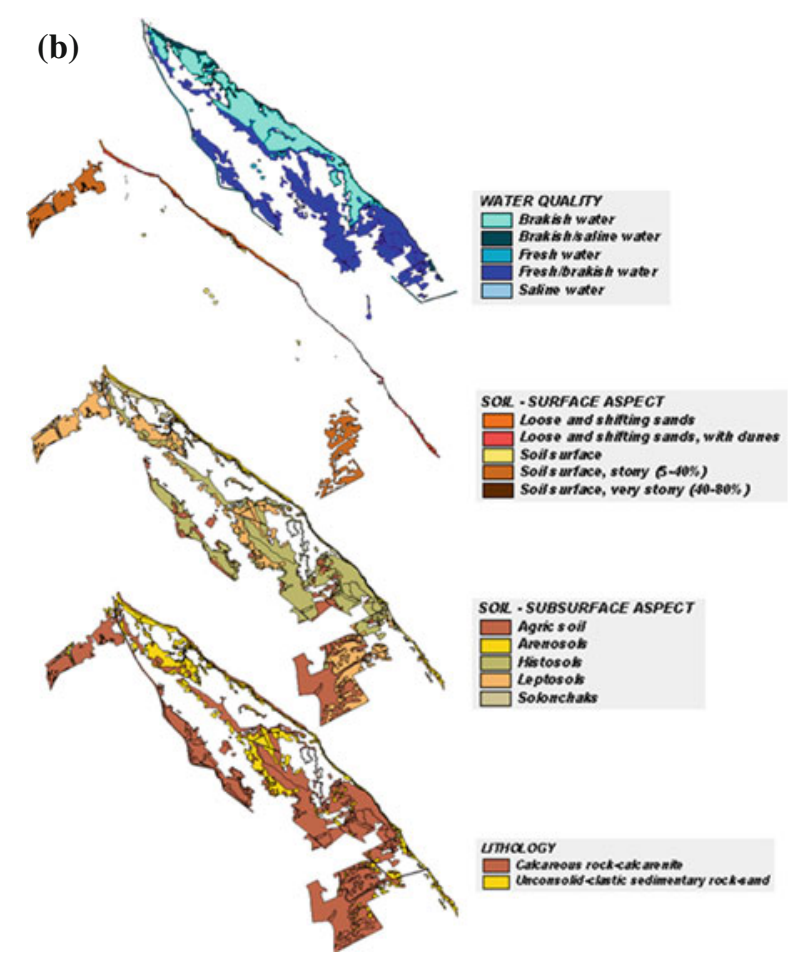

but correspond to different habitats. The discrimination of such habitats requires the integration of the additional environmental attributes reported in Table 4, per each input. The remaining code components correspond to information such as specific plant height that do not influence the mapping algorithm nor cannot be easily measured from remote sensed data without LIDAR data. b GIS input layers including, per each LCCS class, the environmental attributes used for habitat disambiguation in LCCS to Annex I/Eunis mapping (i.e., water quality; soilsurface aspect; soil subsurface aspect; lithology) 
Table 6 Decision rules for LCCS to ANNEX1/EUNIS mapping
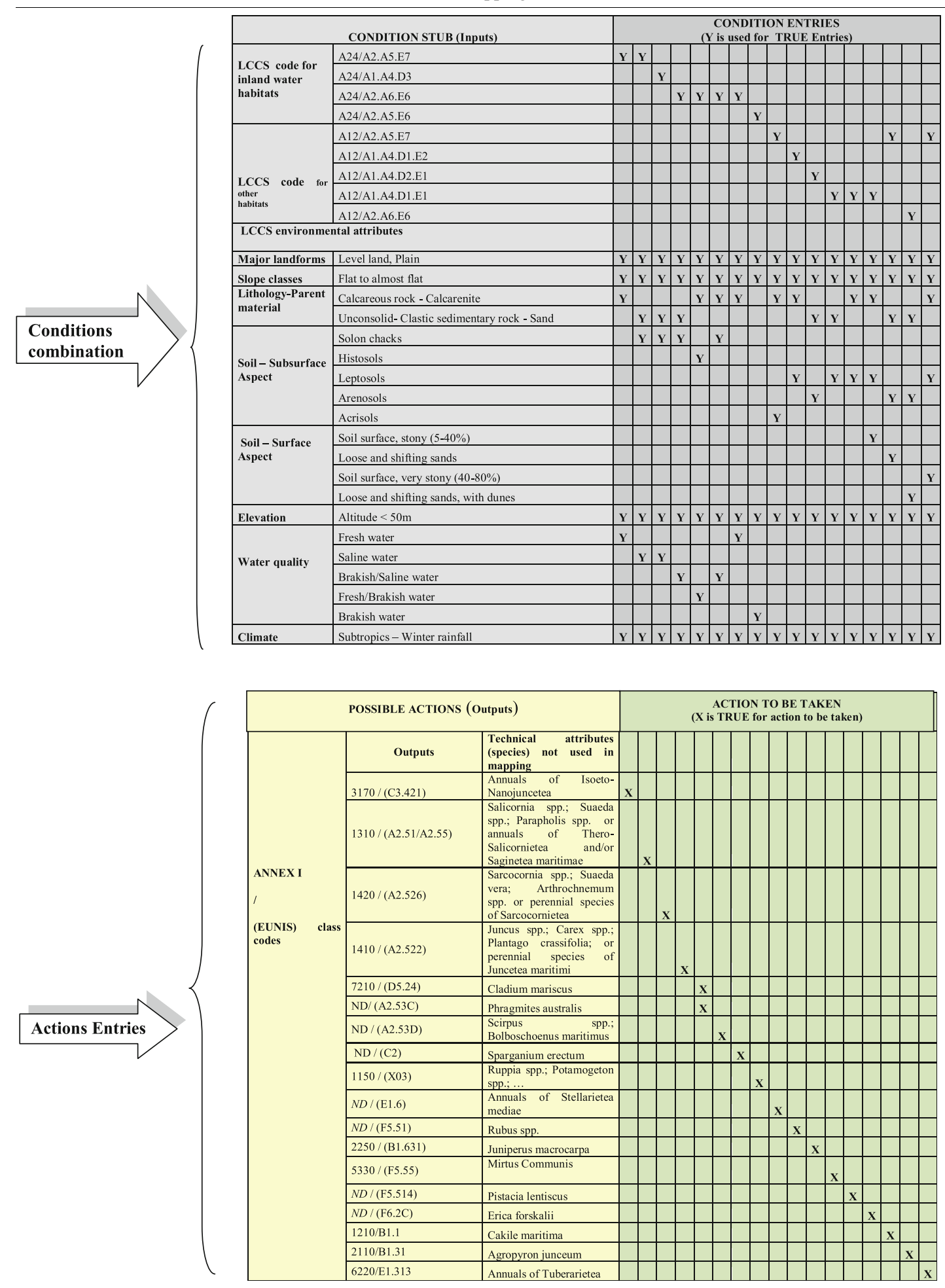

Not_Defined (ND) is used when no AnnexI code is available 

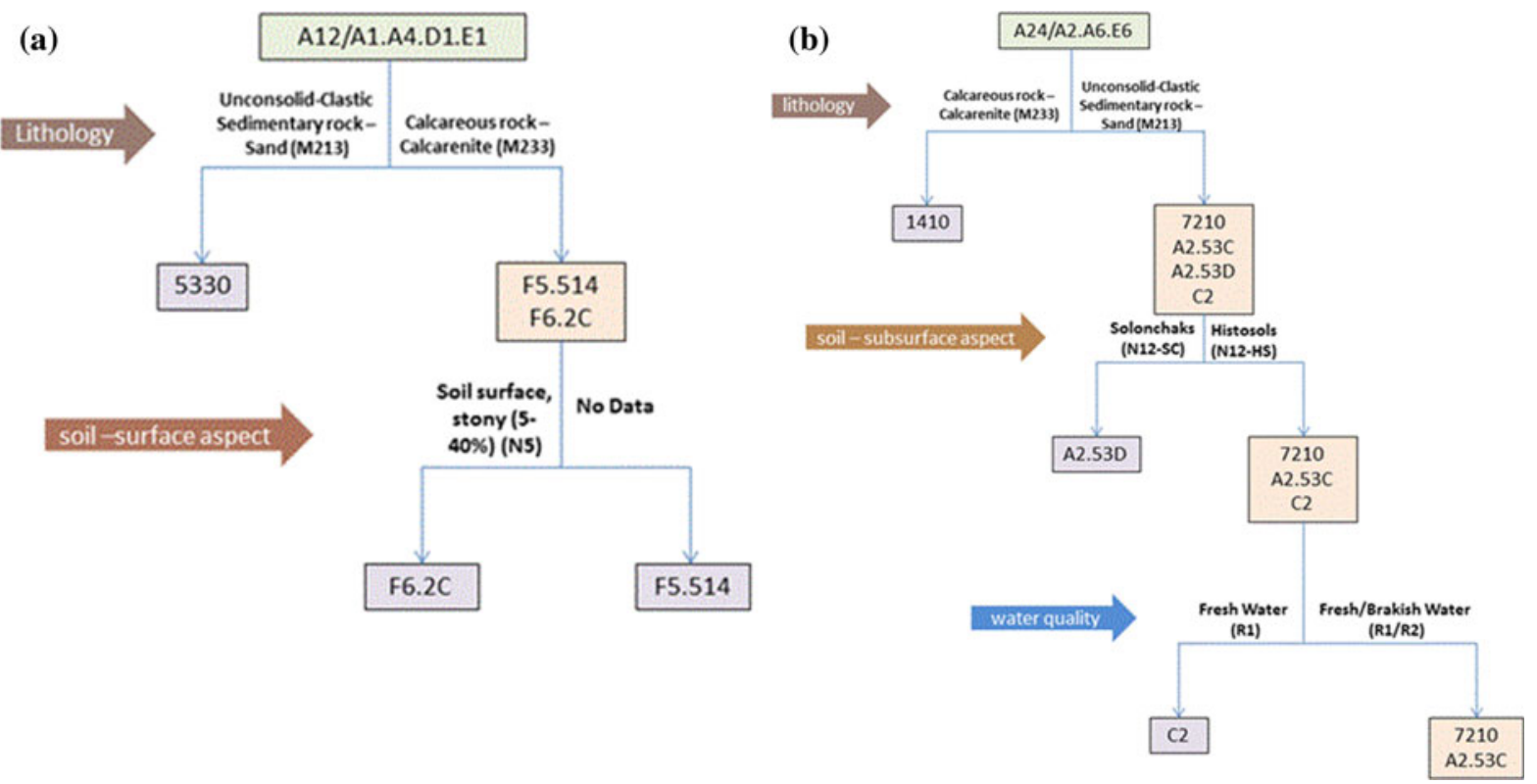

Fig. 4 Graphical representation of the decision actions and condition combination for discriminating: a The habitats associated to LCCS class A12/A1.A4.D1.E1 (i.e. terrestrial vegetated natural and semi-natural woody shrubs broadleaved

deciduous). b The habitats associated to LCCS class A24/ A2.A6.E6 (i.e., natural and semi.natural aquatic vegetated herbaceous graminoids perennial)

Fig. 5 Output habitat map including both Annex I and EUNIS habitats with the latter used only when no Annex I codes exist to label the remaining habitat types of the study site

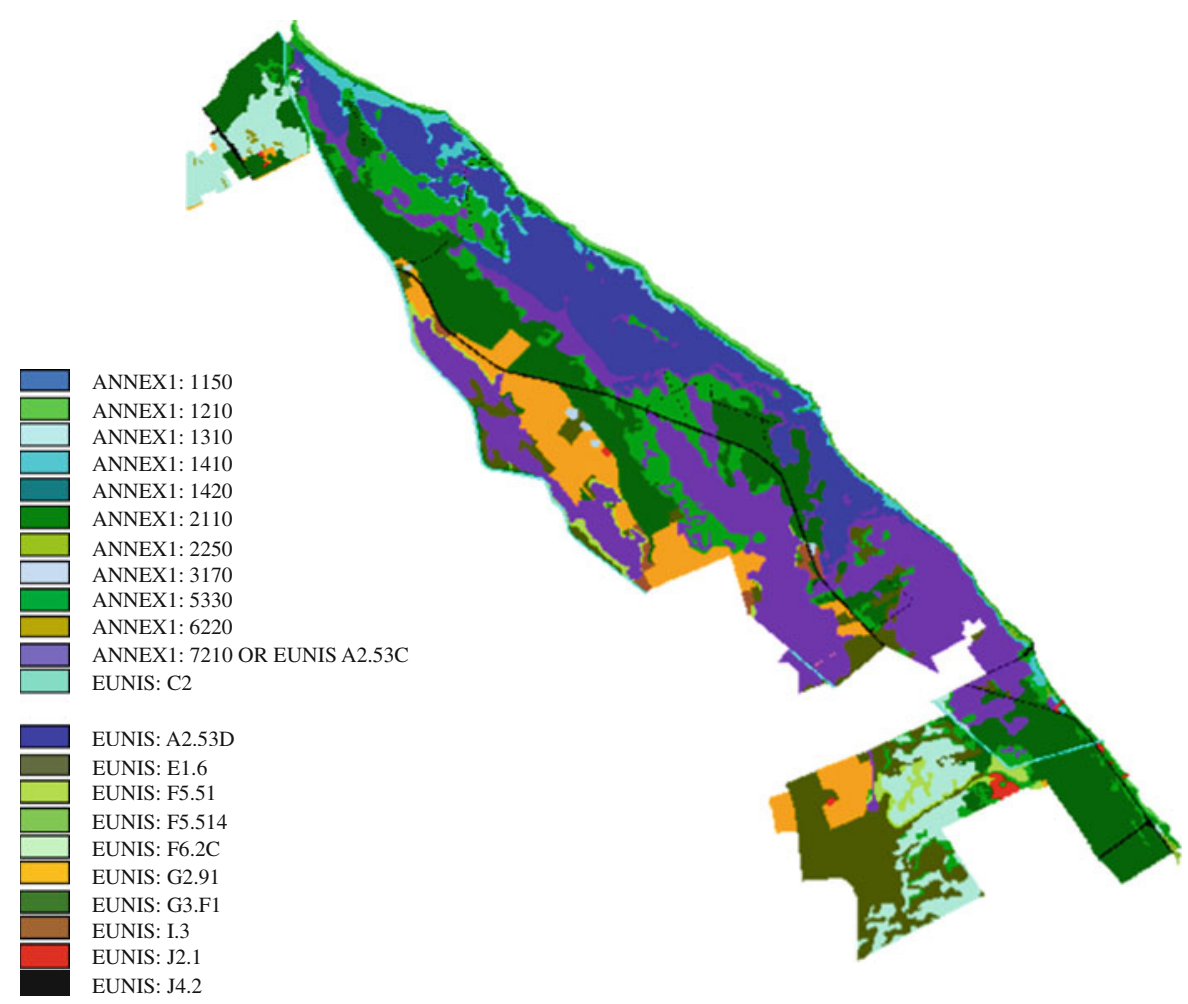




\section{Conclusions}

Land cover maps are at the basis of habitat maps and biodiversity indicator extraction. The selection of an appropriate LC/LU classification system for habitat mapping applications is a crucial issue for long term monitoring. It is particularly important when working with remote sensing imagery at very high spatial resolution due to the complexity of class description and the limited spectral resolution (few spectral bands) that requires multi-temporal imagery and the integration of ancillary data in order to minimize uncertainty in mapping (Lechner et al. 2012).

The qualitative review of CLC, IGBP and LCCS for habitat mapping oriented applications in Mediterranean sites indicates that LCCS allows the finest discrimination of natural and semi-natural types with respect to CLC and IGBP by using the simple pure land cover classifiers of the Modular-Hierarchical phase. This facilitates the subsequent translation of LC/LU into habitat maps based on the additional use of LCCS environmental and technical attributes. The selection of these attributes depends on expert knowledge which, in this study, appeared mandatory for achieving an appropriate class description very close to specific habitat types. As a result, the FAO-LCCS scheme can be considered as an appropriate and userfriendly framework for long-term monitoring of the conservation status of habitats as expert knowledge can be easily embedded in such a framework.

The introduction of new fields for a more detailed description of specific LCCS classifiers and to capture important expert knowledge information is recommended for facilitating the exploitation of the opportunity offered by VHR EO satellite imagery to regularly update LC/LU and habitat maps for fine-grain change detection. More specifically, a new field should be added to the LCCS classifier "Life Cycle" (Leaf type/phenology) to indicate the maximum biomass and flowering periods of perennial and annual vegetated classes, respectively. A new field should also be added to the LCCS classifier "Water Seasonality", to indicate the start-end months of the flooding period. The proposed additional information can be used for appropriate multi-temporal EO image selection and classification improvement. Such information can be very useful for the automatic discrimination of LC/LU classes which might have similar spectral signatures when only a single date EO image is used in the classification process.
Food and Agricultural Organisation has recently developed a so called LCML (Land Cover Meta Language) aiming at classifying LC features with simple groups of elements arranged in different ways in order to describe the more complex semantic in any separate application ontology. Classes derived by LCML can be customized to user requirements, even though maintaining common identities between users. LCML is at the basis of a new version of LCCS (v.3, not yet published) that will be much more flexible and efficient than the previous version.

This research demonstrates that LCCS shows the overall lowest distances (greatest similarity) to almost all habitat taxonomies but Annex I as the latter does not include artificial and agricultural classes. EUNIS and GHCs show the greatest similarity to LCCS, with the last two sharing similar building rules and categories.

The work was carried out in the framework of the BIO_SOS project (www.biosos.eu) aiming to long term biodiversity monitoring from space, not only within and in the neighbouring of Natura 2000 sites but also in other endangered landscapes of conservation significance.

Acknowledgments This work has received funding from the European Union's Seventh Framework Programme FP7/ 2007-2013, SPA.2010.1.1-04: "Stimulating the development of GMES services in specific area", under grant agreement 263435, project title: BIOdiversity Multi-Source Monitoring System: from Space To Species (BIO_SOS) coordinated by CNR-ISSIA, Bari-Italy (http://www.biosos.eu). The authors of this paper thank Ing. Andrea Baraldi, from the Italian one-man company BACRES, for useful suggestions and discussion about LC classification systems. He was a partner of BIO_SOS until 15 Sept 2012. The authors wish also to thank the Editor in Chief and the two anonymous reviewers for their competence and willingness to help through appropriate solicitations.

Open Access This article is distributed under the terms of the Creative Commons Attribution License which permits any use, distribution, and reproduction in any medium, provided the original author(s) and the source are credited.

\section{References}

Ahlqvist O (2004) A parameterized representation of uncertain conceptual spaces. Trans GIS 8(4):493-514

Ahlqvist O (2005) Using uncertain conceptual spaces to translate between land cover categories. Int J Geogr Inf Sci 19(7):831-857

Ahlqvist O (2008) Extending post classification change detection using semantic similarity metrics to overcome class 
heterogeneity: a study of 1992 and 2001 National land Cover Database changes. Remote Sens Environ 112(3):1226-1241

Amoruso N, Baraldi A, Tarantino C, Blonda P (2009) Spectral rules and geostatistic features for characterizing olive groves in QuickBird images. Proc IEEE Trans Geosci Conf South Africa July 2009, IEEE Cat. No. 078-1-4244-33957/09, IV 228-IV 231

Belward AS (ed) (1996) The IGBP-DISGlobal1 km Land Cover Data Set 'DISCOVER': proposal and implementation plans. Report WP No. 13, IGBP-DIS. Stockholm, Sweden

Bossard M, Feranec J, Otahel J (2000) CORINE land cover technical guide-addendum 2000. Technical Report, 40, EEA

Boteva D, Griffiths G, Dimopoulos P (2004) Evaluation and mapping of the conservation significance of habitats using GIS: an example from Crete, Greece. J Nat Conserv 12:237-250

Bruzzone L, Cossu R, Vernazza G (2004) Detection of landcover transitions by combining multidate classifiers. Pattern Recogn Lett 25(13):1491-1500

Bunce RGH, Metzger MJ, Jongman RHG, Brandt J, de Blust G, Elena-Rossello R, Groom GB, Halada L, Hofer G, Howard DC, Kovàř P, Mücher CA, Padoa Schioppa E, Paelinx D, Palo A, Perez Soba M, Ramos IL, Roche P, Skånes H, Wrbka T (2008) A standardized procedure for surveillance and monitoring European habitats and provision of spatial data. Landscape Ecol 23:11-25

Bunce RGH, Bogers MMB, Evans D (2010) D 4.2: rule based system for Annex I habitats. Version 3. Doc. Ref.: EBONED4.2, 2.6. http://www.ebone.wur.nl/NR/rdonlyres/90F1C7 18-8F31-447D-BEF1-CBBC3A61D4E7/106197/EBONED 42KeyAnnex1.pdf)

Bunce RGH, Bogers MMB, Roche P, Walczak M, Geijzendorffer IR, Jongman RHG (2011) Manual for habitat surveillance and monitoring and vegetation in temperate, Mediterranean and desert biomes. Alterra-EBONE_Handbook_v20110131. http://www.ebone.wur.nl/NR/rdonlyres/DADAAB1E-F07C4AA3-8621-20548A9B7DE6/135332/report2154.pdf

Congalton RG, Green K (2009) Assessing the accuracy of remotely sensed data: principles and practices, 2 nd edn. CRC Press, Boca Raton

Council of the European Union (2007) Council Directive 92/43/ EEC of 21 May 1992 on the conservation of natural habitats and of wild fauna and flora, version 1.1.2007. http://ec. europa.eu/environment/nature/legislation/habitatsdirective/ index_en.htm

Davies CE, Moss D (2002) EUNIS habitat classification. Final report to the European topic centre of nature protection and biodiversity, European Environment Agency, Swindon

Di Gregorio A, Jansen LJM (1998) Land Cover Classification System (LCCS): classification concepts and user manual. GCP/RAF/287/ITA Africover-East Africa Project in cooperation with AGLS and SDRN. Nairobi, Rome

Di Gregorio A, Jansen LJM (2005) Land Cover Classification System (LCCS): classification concepts and user manual. Food and Agriculture Organization of the United Nations, Rome

Dimopoulos P, Bergmeier E, Fisher P (2005) Monitoring and conservation status assessment of habitat types in Greece: fundamentals and exemplary cases. Ann Bot 5:7-20
Feng C-C, Flewelling DM (2004) Assessment of semantic similarity between land use/land cover classification systems. Comput Environ Urban Syst 28:229-246

Feola S, Carranza ML, Schaminée JHJ, Janssen JAM, Acosta ATR (2011) EU habitats of interest: an insight into Atlantic and Mediterranean beach and foredunes. Biodivers Conserv 20:1457-1468

Fisher DL (1966) Data, documentation and decision tables. Comm ACM 9(1):26-31. doi:10.1145/365153.365163

Fritz S, See L (2008) Identifying and quantifying uncertainty and spatial disagreement in the comparison of Global Land Cover for different applications. Glob Change Biol 14(5): $1057-1075$

GOFC-GOLD report n.21 (2004) http://www.fao.org/gtos/gofcgold/docs/GOLD_20.pdf

Heller NE, Zavaleta ES (2009) Biodiversity management in the face of climate change: a review of 22 years of recommendations. Biol Conserv 142:14-32

Herold M, Mayaux P, Woodcock CE, Baccini A, Schmullius C (2008) Some challenges in global land cover mapping: an assessment of agreement and accuracy in existing $1 \mathrm{~km}$ datasets. Remote Sens Environ 112:2538-2556

Jansen LJM, Di Gregorio A (2002) Parametric land cover and land-use classifications as tools for environmental change detection. Agric Ecosyst Environ 91:89-100

Kosmidou V, Petrou Z, Lucas R, Tomaselli V, Petrou M, Bunce RGH, Bogers MMB, Mücher CA, Tarantino C, Blonda P, Baraldi A (2012) Software for habitat maps production. BIO_SOS Biodiversity Multisource Monitoring System: from Space TO Species (BIO_SOS) Deliverable D6.10. http://www.biosos.eu

Lechner AM, Langford WT, Bekessy SA, Jones SD (2012) Are landscape ecologists addressing uncertainty in their remote sensing data? Landscape Ecol. doi:10.1007/s10980-0129791-7

Lengyel S, Kobler S, Kutnar L, Framstad E, Henry PY, Babij V, Gruber B, Schmeller D, Henle K (2008) A review and a framework for the integration of biodiversity monitoring at the habitat level. Biodivers Conserv 17:3341-3356

Moss D, Wyatt BK (1994) The CORINE Biotopes Project: a database for conservation of nature and wildlife in the European Community. Appl Geogr 14:327-349

Mücher CA, Hennekens SM, Bunce RGH, Schaminée JHJ, Schaepman ME (2009) Modelling the spatial distribution of Natura 2000 habitats across Europe. Landsc Urban Plan 92(2):148-159

Nagendra H (2001) Using remote sensing to assess biodiversity. Int J Remote Sens 22:2377-2400

Neumann K, Herold M, Hartley A, Schmullius C (2007) Comparative assessment of CORINE2000 and GLC2000: spatial analysis of land cover data for Europe. Int J Appl Earth Obs 9:425-437

Perera AH, Drew CA, Johnson CJ (eds) (2012) Expert knowledge and its application in landscape ecology. Springer, New York. doi:10.1007/978-1-4614-1034-8

Petermann J, Ssymank A (2007) Natura 2000 and its implications for the protection of plant syntaxa in Germany with a case study on grasslands. Ann Bot 7:5-18

Pooch UW (1974) Translation of decision tables. ACM Comput Surv 6(2):125-151. doi:10.1145/356628.356630 
Raunkiaer C (1934) The life forms of plants and statistical plant geography, being the collected papers of C. Raunkiaer, Clarendon

Salafsky N, Salzer D, Ervin J, Boucher T, Ostlie W (2003) Conventions for defining, naming, measuring, combining, and mapping threats in conservation: an initial proposal for a standard system. Conservation Measures Partnership, Washington, DC

Tchuenté ATK, Roujean JL, De Jomg SM (2011) Comparison and relative quality assessment of the GLC2000, GLOBCOVER, MODIS and ECOCLIMAP land cober data sets at the African continental scale. Int $\mathrm{J}$ Appl Earth Obs 13:207-219

Tomaselli V, Blonda P, Marangi C, Lovergine F, Baraldi A, Mairota P, Terzi M, Muncher S (2011) Report on relations between vegetation types derived from land cover maps and habitats. BIO_SOS Biodiversity Multisource Monitoring System: from Space TO Species (BIO_SOS) Deliverable D6.1. http://www.biosos.eu

Tomaselli V, Tenerelli P, Sciandrello S (2012) Mapping and quantifying habitat fragmentation in small coastal areas: a case study of three protected wetlands in Apulia (Italy). Environ Monit Assess 184(2):693-713

Townsend PA, Lookingbill TR, Kingdon CC, Gardner RH (2009) Spatial patter analysis for monitoring protected areas. Remote Sens Environ 113:1410-1420

Turner MG, Gardner RH, O'Neill RV (2001) Landscape ecology in theory and practice: pattern and process. Springer, New York

Vačkáŕ D, Chobot K, Orlitová E (2012) Spatial relationship between human population density, land use intensity and biodiversity in the Czech Republic. Landscape Ecol. doi: 10.1007/s10980-012-9779-3

Vanden Borre J, Paelinckxa D, Mücher CA, Kooistra L, Haest B, De Blust G, Schmidt AM (2011) Integrating remote sensing in Natura 2000 habitat monitoring: prospects on the way forward. J Nat Conserv 19:116-125

Williams JW, Jackson ST (2007) Novel climates, no-analog communities, and ecological surprises. Front Ecol Environ $5: 475-482$ 